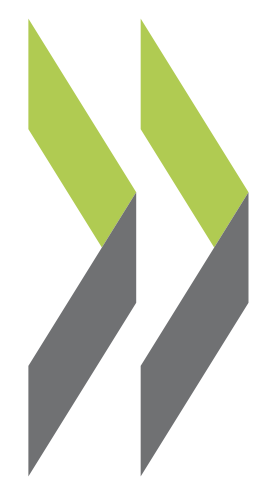

OECD Economics Department Working Papers No. 602

$$
\begin{array}{r}
\text { The Contribution } \\
\text { of Economic Geography } \\
\text { to GDP Per Capita }
\end{array}
$$

Hervé Boulhol,

Alain de Serres,

Margit Molnar 
Organisation de Coopération et de Développement Économiques

Organisation for Economic Co-operation and Development

14-Apr-2008

ECONOMICS DEPARTMENT

English - Or. English

THE CONTRIBUTION OF ECONOMIC GEOGRAPHY TO GDP PER CAPITA

ECONOMICS DEPARTMENT WORKING PAPER No. 602

By

Hervé Boulhol, Alain de Serres and Margit Molnar

All Economics Working Papers are available through the OECD's internet web site at the www.oecd.org/Working_Papers

JT03244071 


\section{ABSTRACT/RÉSUMÉ}

\section{The Contribution of Economic Geography to GDP Per Capita}

This paper examines how much of the dispersion in economic performance across OECD countries can be accounted for by economic geography factors. More specifically, two aspects of economic geography are examined, namely the proximity to areas of dense economic activity and endowments in natural resources. To do so, various indicators of distance to markets, transportation costs, and dependence on natural resources are added as determinants in an augmented Solow model, which serves as a benchmark. Three measures of distance to markets are found to have a statistically significant effect on GDP per capita: the sum of bilateral distances, market potential and the weighted sum of market access and supplier access. And the estimated economic impact is far from negligible. The reduced access to markets relative to the OECD average could contribute negatively to GDP per capita by as much as $10 \%$ in Australia and New Zealand. Conversely, a favourable impact of around 6-7\% of GDP is found in the case of two centrally-located countries: Belgium and the Netherlands. Endowments in natural resources are also found to have a significant positive effect on GDP per capita, suggesting that OECD countries have, on average, escaped the natural resource curse or severe forms of the Dutch disease. The paper provides also some tentative evidence that spending on R\&D and human capital might have a stronger effect on GDP per capita in countries with a higher degree of urban concentration.

JEL classification codes: F12, O40, Q30, R11

Key words: GDP-per-capita; economic geography; distance; transport costs; natural resources

\section{La contribution de l'économie géographique au PIB par tête}

Ce papier analyse la contribution des facteurs géographiques à la dispersion des performances économiques entre pays de l'OCDE. Plus particulièrement, deux aspects de l'économie géographique sont étudiés : la proximité de zones denses d'activités économiques et les dotations en ressources naturelles. Pour se faire, divers indicateurs de distance par rapport aux marchés, de coûts de transports, et de dépendance envers les ressources naturelles sont ajoutés comme déterminants dans un modèle de Solow augmenté, utilisé comme référence. Trois mesures de distance sont estimées avoir un effet significatif sur le PIB par habitant: la somme des distances bilatérales, le potentiel de marché et la somme pondérée de l'accès aux marchés et de l'accès aux fournisseurs. De plus, l'impact économique estimé est loin d'être négligeable. L'éloignement par rapport aux marchés pourrait pénaliser l'Australie et la Nouvelle Zélande, par rapport à la moyenne des pays de l'OCDE, à hauteur d'environ 10\% de PIB. A l'inverse, la Belgique et les Pays Bas bénéficieraient de leur position centrale pour environ 6-7\% de PIB. Les dotations en ressources naturelles sont estimées avoir un effet positif significatif sur le PIB par habitant, suggérant que les pays de l'OCDE ont, en moyenne, échappé au fléau des ressources naturelles ou aux formes sévères de la maladie hollandaise. Des premières indications suggèrent également que les dépenses en $R \& D$ et en capital humain peuvent avoir un effet plus fort sur le PIB par tête dans les pays ayant un fort degré de concentration urbaine.

Classification JEL : F12, O40, Q30, R11

Mots-clés : PIB par tête ; économie géographique ; distance ; coûts de transport ; ressources naturelles

Copyright OECD, 2008

Application for permission to reproduce or translate all, or part of, this material should be made to: Head of Publications Service, OECD, 2 rue André Pascal, 75775 Paris Cedex 16, France. 


\section{TABLE OF CONTENTS}

\section{The Contribution of Economic Geography to GDP Per Capita}

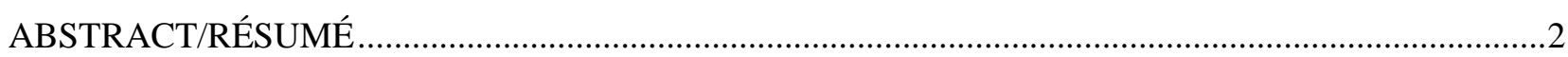

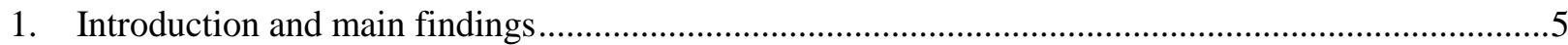

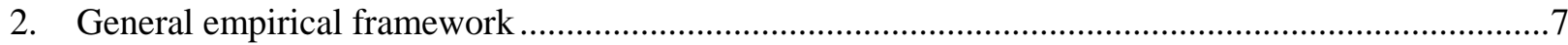

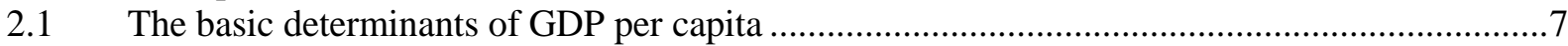

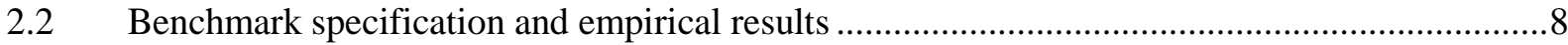

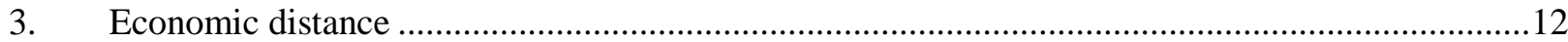

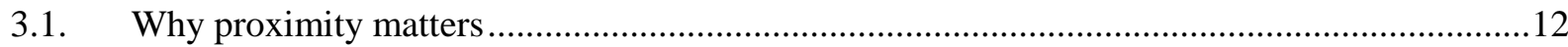

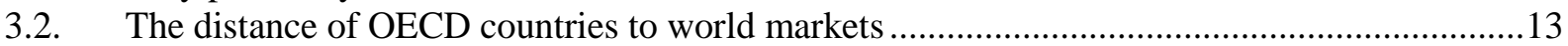

3.3. Empirical analysis: Augmented Solow model and proximity ...............................................18

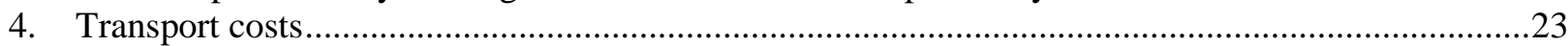

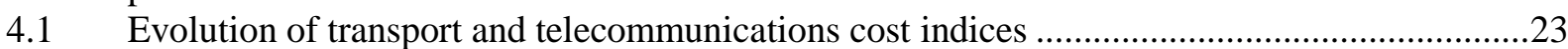

4.2 Impact of transport costs on openness to trade and GDP per capita.........................................29

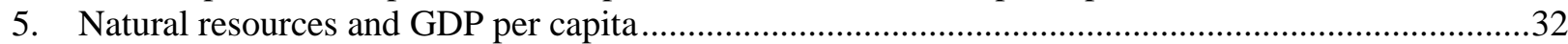

$5.1 \quad$ Impact of resource endowments on growth: the main channels .............................................32

5.2 Differences in resource endowments across OECD countries .................................................33

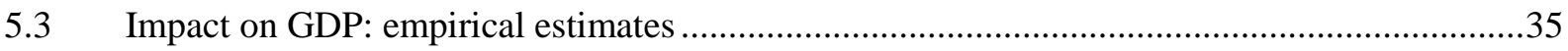

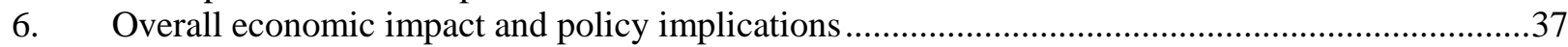

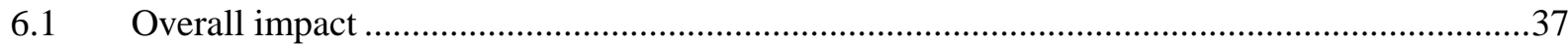

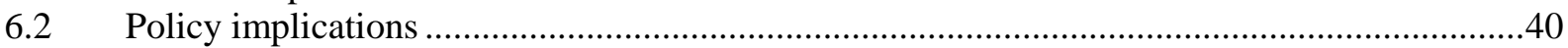

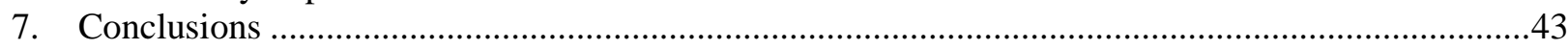

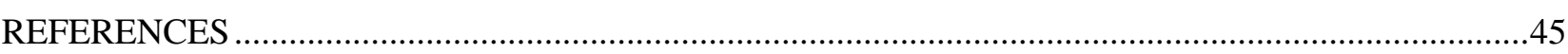

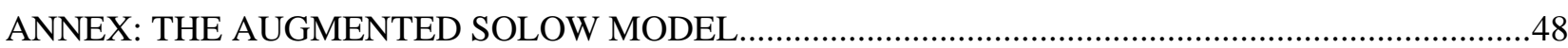

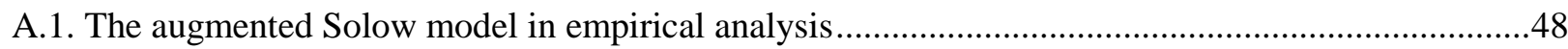

A.2. Formal presentation of the model ………..................................................................................

\section{Boxes}

Box 1. Construction of market access and supplier access measures.......................................................14

\section{Tables}

1. Basic framework: Regression results

2. Measures of proximity/distance to markets, 2005

3. Domestic and foreign components of market potential and market access, 2005

4. Basic framework with proximity variables

5. Sensitivity of proximity effects across specifications

6. Basic framework with openness to trade

7. Basic framework with natural resources

8. Impact of market and supplier access and natural resources on GDP per capita, per cent

9. Size of country fixed effects and share of variance explained by fixed effects

10. Geography and the effectiveness of structural policies 


\section{Figures}

1. Basic framework: Contributions of explanatory variables

2. Market potential, 2005

3. Estimated impact of market and supplier access on GDP per capita

4. Overall transport costs and contribution from three sub-components

5. Total average transport cost

6. Average maritime transport cost

7. Real cost of one minute international telephone call from selected origin countries

8. Estimated impact of transportation costs on GDP per capita

9. Measures of natural resource endowments excluding agriculture

10. Estimated impact of natural resources on GDP per capita 
ECO/WKP(2008)10

\title{
The Contribution of Economic Geography to GDP Per Capita ${ }^{1}$
}

\author{
By Hervé Boulhol, Alain de Serres and Margit Molnar
}

\section{Introduction and main findings}

1. Over the past several years, the OECD has quantified the impact of structural policies on employment, productivity and GDP per capita (e.g. OECD 2003, 2006) The results from these studies, which have built on a vast academic literature, have contributed to a better understanding of the main channels linking policies to labour and product market outcomes in OECD countries. In doing so, they have also underscored the limits to the understanding of economic growth: only a limited part of the crosscountry dispersion in GDP levels and growth rates can be explained by quantifiable policy levers, at least on the basis of standard macro-growth regression analysis.

2. This paper examines how much of the cross-country dispersion in economic performance can be accounted for by economic geography factors. To do so, an augmented Solow model is used as a benchmark. The choice is motivated by the fact that this model has served as the basic framework in previous work on the determinants of growth, thereby ensuring some continuity. It has long been recognised, however, that while providing a useful benchmark to assess the contributions of factor accumulation as a source of differences in GDP per capita, the basic Solow growth model ignores potentially important determinants. For instance, it leaves a large portion of growth to be explained by the level of technology, which is assumed to grow at a rate set exogenously.

3. In order to bridge some of the gaps, extensions of the model in the literature have generally taken four types of (partly related) directions: $i$ ) R\&D and innovation, ii) goods market integration and openness to international trade, iii) quality of institutions, and $i v$ ) economic geography. The focus of this paper is on economic geography, although this is not totally independent from the other factors, in particular international trade. More specifically, for the purpose of this study, the concept of economic geography is examined through endowments of natural resources and the proximity to areas of dense economic activity.

4. The key point of the latter aspect of geography is the recognition that proximity may have a favourable impact on productivity, through various channels operating via product and labour markets. In the case of product markets, one of the key channels is that proximity induces stronger competition between producers, thus encouraging efficient use of resources and innovation activity. Another is that an easy access to a large market for consumers and suppliers of intermediate goods allows for the exploitation of increasing returns to scale. Furthermore, the presence of large markets allows for these scale effects to be realised without adversely affecting competition. The scope for exploiting higher returns to scale is hampered by distance to major markets, both within and across countries, due to transportation costs. Transportation costs also reduce the scope for specialisation according to comparative advantage, another important driver of gains from trade along with the ability to reap scale economies.

1. The authors would like to thank numerous OECD colleagues, in particular Sven Blöndal, Jørgen Elmeskov, Christian Gianella, David Haugh, Peter Hoeller, Vincent Koen, Jean-Luc Schneider and Andreas Woergoetter, for their valuable comments as well as Philippe Briard and Martine Levasseur for technical assistance and Caroline Abettan for editorial support. The paper has also benefited from comments by members of the Working party No. 1 of the OECD Economic Policy Committee. 
5. While the economic geography literature focuses mainly on trade linkages, a parallel literature on urban and spatial economics puts more emphasis on agglomeration externalities as a benefit from operating in an area of dense economic activity. Such externalities may include economies of scale related to infrastructure and other public services, as well as the potential gains associated with the access to a large pool of workers, and localised knowledge spillovers. In principle, it is possible to provide some quantification of these benefits, using standard measures of economic density, such as the share of population living in cities. In practice, such measures are highly endogenous to economic development and finding appropriate instruments to address the endogeneity problem is beyond the scope of this paper. As a result, this aspect is only examined in a very tentative way in the final section of the paper.

6. As for the second aspect of geography examined in this paper, a country richly endowed in natural resources benefits from a cheaper access to a factor of production and, perhaps more importantly, from a rent on the exploitation of the resources. This would suggest that natural resource endowment would, in principle, have a positive influence on GDP per capita. However, historical developments have shown that this is not necessarily the case, and in fact the direction of the effect of natural resources on economic performance remains unsettled in the empirical literature. One fact that could lead to a negative effect in the long-run is the well-known Dutch disease, but other explanations, based on political economy arguments, have also been put forward.

7. The empirical strategy pursued in the paper is as follows. In section 2, the augmented Solow model, which is used as the basic framework, is first briefly described and estimated both in level and in error-correction forms, over a sample of 21 OECD countries over the period 1970-2004. The influence of proximity to major markets on GDP per capita is investigated in section 3, introducing in the benchmark model various indicators of distance to markets, such as measures of market potential, market and supplier access, as well as the sum of distances to world markets and population density. The various measures of distance to markets are all found to have a statistically significant effect on GDP per capita, with the exception of population density. The estimated economic impact varies somewhat across specifications, but it is far from negligible. For instance, the lower access to markets relative to the OECD average could contribute negatively to GDP per capita by as much as $10 \%$ in Australia and New Zealand. Conversely, the benefit from a favourable location could be as high as 6-7\% of GDP in the case of Belgium and the Netherlands.

8. In section 4, the impact of distance is alternatively examined via the more specific channel of transportation and telecommunication costs. To this end, broad indicators of weight-based transportation costs covering maritime, air and road shipping have been constructed for 21 OECD countries over the period 1973-2004, along with an indicator of the cost of international telecommunications. Based on these indicators, there is little evidence that the importance of distance in the transportation of goods has diminished during the past two or three decades (though transport costs may have fallen relative to the value of transported goods). In contrast, the cost of international telecommunications has fallen in all countries to the point where it is basically no longer significant anywhere. Overall, transportation costs are found to have a negative and significant effect on GDP per capita through their effect on international trade. Based on these estimates, differences in transport costs relative to the OECD average contribute to reduce GDP per capita by between $1.0 \%$ and $4.5 \%$ in Australia and New Zealand. At the other end, the lower transport costs for Canada and the United States contribute to raise GDP per capita relative to the average OECD country, but only by a small margin varying between $0.5 \%$ and $2.5 \%$. The quantitatively smaller effects than those found on the basis of measures of economic distance are consistent with transportation costs being only one aspect of costs related to distance.

9. The significance of endowment in natural resources is examined in section 5 by adding a measure of net exports of primary products (excluding agriculture) as a determinant in the benchmark model. This variable is only an imperfect indicator of resource endowments but is nonetheless found to have a positive 
effect on GDP per capita, suggesting that OECD countries have, on average, escaped the natural resource curse or severe forms of Dutch disease. Not surprisingly, the main beneficiaries of rich resource endowments are Norway and, to a lesser extent, Australia and Canada. Higher net exports of primary products as a share of GDP relative to the OECD average in the early 2000s could have contributed to raise GDP per capita by $8 \%$ in Norway and by $2 \%$ in Australia and Canada.

10. Most of the geography factors discussed in this paper cannot be influenced by policy or are only affected by policy in indirect ways. Nevertheless, a number of policy issues are addressed in Section 6, which also provides a summary of the combined economic impact of the geographic variables used in the empirical analysis.

\section{General empirical framework}

11. A basic empirical framework is required in order to assess the importance of economic geography in determining GDP per capita. Against the background of earlier OECD analysis in this area, this section briefly reviews the basic determinants of GDP per capita, discusses alternative specifications in terms of levels and changes over time, and reports the results of an empirical analysis using only the basic determinants. The remainder of the paper will then examine whether economic geography variables can account for some of the variance in GDP per capita left unexplained by the basic determinants.

\subsection{The basic determinants of GDP per capita}

12. The empirical framework used to assess the influence of economic geography determinants is the Solow (1956) model augmented with human capital. The model has been widely used in the empirical growth literature, owing largely to its simplicity and flexibility. For instance, despite being derived from a specific framework, the empirical version of model is sufficiently general to be consistent with some endogenous growth models (Arnold et al., 2008).

13. The Solow model has been widely used as a theoretical framework to explain differences across countries in income levels and growth patterns. The model is based on a simple production function with constant returns-to-scale technology. In the augmented version of the model (Mankiw, Romer and Weil, 1992), output is a function of human and physical capital, as well as labour (working-age population) and the level of technology. Under a number of assumptions about the evolution of factors of production over time, the model can be solved for its long-run (steady-state) equilibrium whereby the path of output per capita is determined by the rates of investment in physical and human capital, the level of technology, and the growth rate of population (see Annex for a detailed derivation). In the steady-state, the growth of GDP per capita is driven solely by technology, which is assumed to grow at a (constant) rate set exogenously in the basic model.

14. The long-run relationship derived from the augmented Solow model can be estimated either directly in its level form, or through a specification that explicitly takes into account the dynamic adjustment to the steady state. Estimates of the long-run relationship in static form have been used in the literature (e.g. Mankiw, Romer and Weil, 1992; Hall and Jones, 1999; Bernanke and Gürkaynak, 2001), in particular in studies focusing on income level differentials across countries. However, since the model has often been used in the empirical growth literature to examine issues of convergence, some form of dynamic specification has been more common. The two types of specification - static or dynamic - can be expected to yield similar results if countries are not too far from their steady states or if deviations from the latter are not too persistent.

15. In principle, a dynamic specification is preferable, even when the interest is mainly on the identification of long-run determinants. This is because persistent deviations from steady state are more 
likely to lead to biased estimates of the long-run parameters in static regressions, especially when the timeseries dimension of the sample is relatively short. In practice, estimating dynamic panel equations is also fraught with econometric problems (Durlauf and Quah, 1999). Furthermore, a major drawback with the most common techniques based on dynamic fixed-effect estimators is that only the intercepts are allowed to vary across countries, implying that all countries converge to their steady-state at the same speed, an assumption unlikely to hold even among developed countries. ${ }^{2}$

16. To address the latter issue, previous studies have relied on the Pooled Mean Group (PMG) estimator, which allows for short-run coefficients and the speed of adjustment to vary across countries, while imposing homogeneity on long-run coefficients (OECD, 2003). However, even though the PMG estimation technique is intuitively appealing and perhaps the most suitable under some conditions, it is not without limitations especially when such conditions are not met. For instance, due to the large number of parameters and the non-linear constraints, the maximum likelihood estimation technique is prone to problems of convergence on local optima. And, experience suggests that parameter estimates can be particularly sensitive in presence of multi-collinearity among regressors, with some parameter values being in such cases too large (and unstable) to be plausible.

17. For the purpose of this study, the model is first re-estimated with only the basic determinants included in the specification, i.e. proxies for investment in physical and human capital, population growth and technical progress. Then, a number of determinants are added to the benchmark specification throughout the rest of the paper, but the set of additional variables is limited to those related to economic geography factors. One exception is the measure of exposure to international trade which, given the importance of geography on trade, is used to assess the impact of transportation costs on GDP per capita (Section 4). The reason for leaving other potential variables out is essentially one of parsimony, i.e. to limit the number of specifications, which quickly runs up as each additional determinant is considered. ${ }^{3}$ However, this implies that potentially significant control variables are not included, with the risk that this entails in terms of biases and robustness of the results as regards the determinants of economic geography. In order to minimise those risks, all specifications include various combinations of country and year fixedeffects and/or linear time trends, all of which are introduced in part to capture omitted variables.

\subsection{Benchmark specification and empirical results}

18. The empirical version of the augmented-Solow model is re-estimated over a panel data set comprising 21 countries and 35 years of observations (1970-2004). In what will serve as the reference model for the rest of the paper, the level of GDP per working-age person in country $i$ and year $t\left(y_{i t}\right)$ is regressed on the rate of investment in the total economy $\left(s_{K, i t}\right)$, the average number of years of schooling of the population aged 25-64, which is used as a proxy for the stock of human capital $\left(h c_{i t}\right)^{4}$ and the growth rate of population $\left(n_{i t}\right)$ augmented by a constant factor introduced as a proxy for the sum of the

2. The implications of imposing invalid homogeneity restrictions on slope parameters in the context of dynamic panel estimates are discussed in Lee, Pesaran and Smith (1997).

3. The reason is that the number of determinants that can be jointly estimated is limited by available degrees of freedom and risks of multi-collinearity. Hence, the variables can only be tested sequentially with the number of possible permutations rising exponentially with the set of determinants. Sala-i-Martin et al., (2004) have proposed a bayesian method to deal with this standard problem in empirical growth analysis.

4. In principle, a measure of investment in human capital should be used to be consistent with the treatment of physical capital in the basic Solow model. In practice, a proxy for the stock - average number of years of schooling - is used due to the absence of an adequate measure of the flow. However, to ensure consistency with the theoretical model, the measure of stock is introduced both in level and first-difference forms, even in the "level" specification. 
trend growth rate of technology and the rate of capital depreciation $(g+d)$, with all variables expressed in $\operatorname{logs} .^{5}$ Technological progress is captured alternatively by a linear time trend or time dummies.

19. The results presented in this paper are based on both a level specification, using a least-square estimator (that corrects for heteroskedasticity and contemporaneous correlations), and an error correction specification, using the pooled mean group (PMG) estimator. Due to persistence in the series, control for first-order serial correlation is systematically made when the level specification is estimated. The functional forms of the equations estimated in level and error-correction forms are respectively specified as follows (see Annex 2 for derivation):

\section{Level specification (ARI)}

$$
\begin{aligned}
& \log y_{i t}=\alpha \cdot \log s_{K, i t}+\beta \cdot \log h c_{i t}+\varphi \cdot \Delta \log h c_{i t}+\gamma \cdot \log \left(n_{i t}+g+d\right)+\varsigma_{i} t+e_{i}+e_{t}+u_{i t} \\
& u_{i t}=\rho \cdot u_{i t-1}+\varepsilon_{i t} \quad, \quad \varepsilon_{i t} \text { i.i.d. }
\end{aligned}
$$

\section{Error-correction specification (Pooled Mean Group)}

$$
\begin{aligned}
\Delta \log y_{i t} & \left.=-\lambda_{i} \cdot \log y_{i t-1}-\left(\alpha \cdot \log s_{K, i t}+\beta \cdot \log h c_{i t}+\gamma \cdot \log \left(n_{i t}+g+d\right)\right)\right] \\
& +a_{0 i} \cdot \Delta \log s_{K, i t}+a_{1 i} \cdot \Delta \log h c_{i t}+a_{2 i} \cdot \Delta \log \left(n_{i t}+g+d\right)+e_{i}+\varsigma_{i} \cdot t+\varepsilon_{i t}
\end{aligned}
$$

where $e_{i}$ and $e_{t}$ are country and year fixed-effects, respectively, and $t$ is a linear time trend. The parameters $\alpha, \beta, \gamma$ and $\varsigma$ are the long-run parameters on the three basic determinants and the time trend. The parameter $\rho$ is the first-order autocorrelation coefficient used in the level specification. ${ }^{6}$ The other parameters capture short-run dynamics and will not be reported in the table of results. Finally, $u_{i t}$ and $\varepsilon_{i t}$ are the residuals.

20. The results from re-estimating the empirical version of the augmented-Solow model are presented in Table 1. The first three columns refer to the level specification and the last two are based on the error-correction specification. Focusing on the level specification, the coefficient on human capital is quite sensitive to the control for fixed effects and or time trends. In particular, it comes out significantly higher when country fixed effects are excluded (Column 2), suggesting that an important part of the information contained in the average number of years of schooling is related to differences in average levels across countries. Moreover, it completely drops out when country-specific time trends are included in the regression in addition to country- and year-fixed effects (Column 3).

5. Following a standard approach in the literature, this constant factor $(g+d)$ is set at 0.05 for all countries (Mankiw et al., 1992).

6. Doing so makes it close to a growth rate or error correction model specification, with constraints imposed on the short-term dynamics (see Beck and Katz, 2004, for further details). In that sense, 1 minus the firstorder correlation parameter can be compared with the annual speed of convergence. 
Table 1. Basic framework: Regression results

Augmented-Solow model ${ }^{1}$

\begin{tabular}{|c|c|c|c|c|c|}
\hline $\begin{array}{l}\text { Dependant variable } \\
\text { GDP per capita }\end{array}$ & $\begin{array}{l}\text { level } \\
\text { AR (1) }\end{array}$ & $\begin{array}{c}\text { level } \\
\text { AR (1) }\end{array}$ & $\begin{array}{l}\text { level } \\
\text { AR (1) }\end{array}$ & $\begin{array}{c}\text { Error } \\
\text { correction } \\
\text { PMG }\end{array}$ & $\begin{array}{c}\text { Error } \\
\text { correction } \\
\text { PMG }\end{array}$ \\
\hline & (1) & (2) & (3) & (4) & (5) \\
\hline \multicolumn{6}{|l|}{ Common parameters } \\
\hline \multirow{2}{*}{ Physical capital } & $0.184 * * *$ & $0.156^{* * *}$ & $0.199 * * *$ & $0.292 * * *$ & $0.572 * * *$ \\
\hline & $(0.019)$ & $(0.024)$ & $(0.017)$ & $(0.030)$ & $(0.059)$ \\
\hline \multirow[t]{2}{*}{ Human capital } & $0.334 * * *$ & $0.792 * * *$ & -0.063 & $0.861 * * *$ & -0.006 \\
\hline & $(0.127)$ & $(0.053)$ & $(0.156)$ & $(0.199)$ & (0.189) \\
\hline \multirow[t]{2}{*}{ Population growth ${ }^{2}$} & -0.006 & -0.016 & -0.003 & $-0.392 * * *$ & $-0.661 * * *$ \\
\hline & $(0.018)$ & $(0.028)$ & (0.018) & $(0.067)$ & (0.101) \\
\hline \multirow[t]{2}{*}{ Time trend } & & & & & $0.015 * * *$ \\
\hline & & & & & $(0.002)$ \\
\hline Rho $^{3}$ & 0.884 & 0.911 & 0.775 & & \\
\hline \multicolumn{6}{|l|}{ Country-specific parameters } \\
\hline \multirow[t]{2}{*}{ Lambda $^{4}$} & & & & $-0.190 * * *$ & $-0.086 * * *$ \\
\hline & & & & $(0.025)$ & $(0.017)$ \\
\hline Time trend & no & no & yes & yes & no \\
\hline \multicolumn{6}{|l|}{ Fixed effects } \\
\hline Country & yes & no & yes & yes & yes \\
\hline Year & yes & yes & yes & no & no \\
\hline \multicolumn{6}{|l|}{ Sample size } \\
\hline Total number of observations & 696 & 696 & 696 & 695 & 695 \\
\hline Number of countries & 21 & 21 & 21 & 21 & 21 \\
\hline
\end{tabular}

Note: Standard errors are in brackets. *: significant at $10 \%$ level; ** at $5 \%$ level; *** at $1 \%$ level.

1. The functional forms corresponding to the "level" and "error-correction" specifications are reported in section 2.2. In the level specification, standard errors are robust to heteroscedasticity and to contemporaneous correlation across panels. In the errorcorrection specification, only long term parameters are reported.

2. The population growth variable is augmented by a constant factor $(g+d)$ designed to capture trend growth in technology and capital depreciation. This constant factor is set at 0.05 for all countries.

3. rho is the first-order auto-correlation parameter.

4. The parameter lambda is the average of the country-specific speed adjustment parameter, $\lambda i$.

21. Turning to the error-correction specification, the results shown in the fourth column are similar to those obtained in the earlier OECD analysis based on an almost identical specification (with country fixed effects and country-specific parameters on the time trend) and the same estimation method (PMG). ${ }^{7}$ The speed of adjustment parameter suggests rapid convergence to the steady-state, a result which is influenced by the introduction of country-specific time trend parameters. ${ }^{8}$ Also, the parameter estimate on human

7. For a direct comparison, see the results reported in OECD (2003), Table 2.4, second column, on page 81.

8. In fact, the inclusion of specific trend parameters distorts the notion of convergence, since it should then be interpreted as convergence to a different steady-state growth rate across countries (Lee, Pesaran and Smith, 1997, and Islam, 1998). It is therefore not surprising that in such case the estimated speed of convergence of around $19 \%$ per annum is higher than when parameter homogeneity is imposed across countries. 
capital suggests a strong effect, with one extra year of schooling leading to an increase in GDP per capita by around $8 \%$ in the long run for the average OECD country. However, here again, the significance of the human capital coefficient depends on whether or not the trend is assumed to be common or country specific (column 5). ${ }^{9}$

Figure 1. Basic framework: Contributions of explanatory variables ${ }^{1}$

Difference to average country, 2000-2004

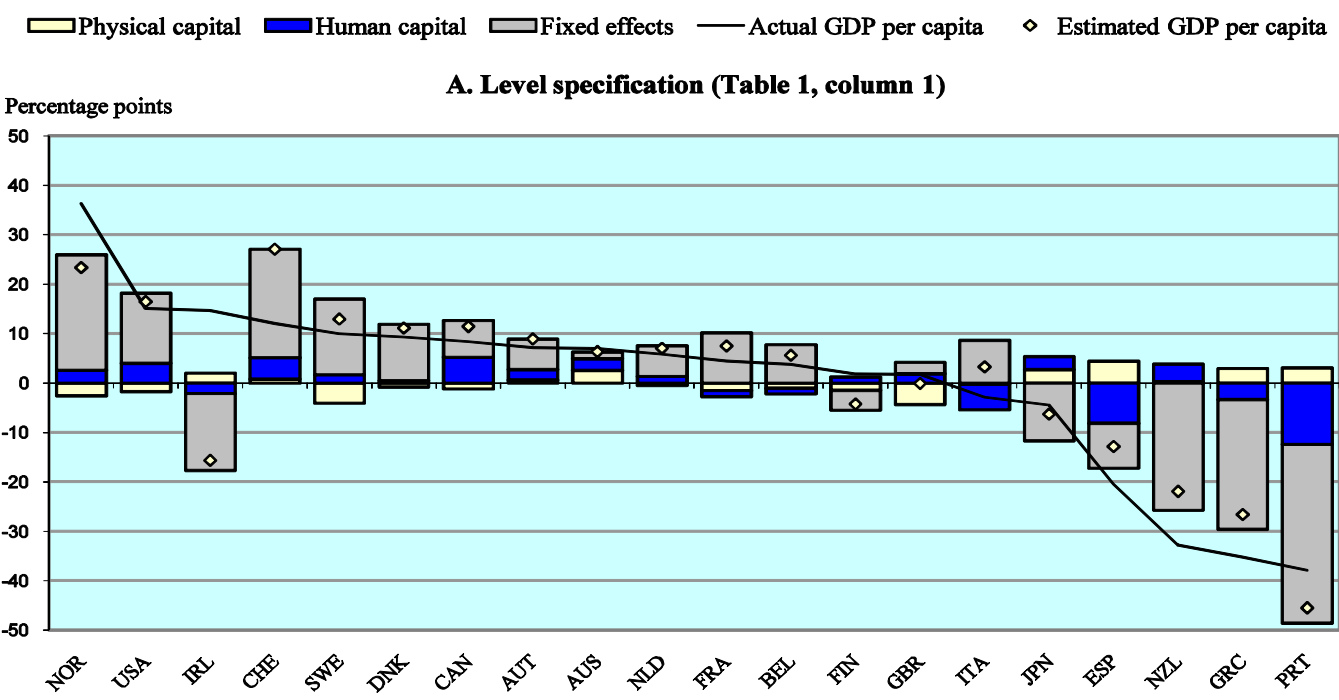

B. Error correction specification (Table 1, column 4)

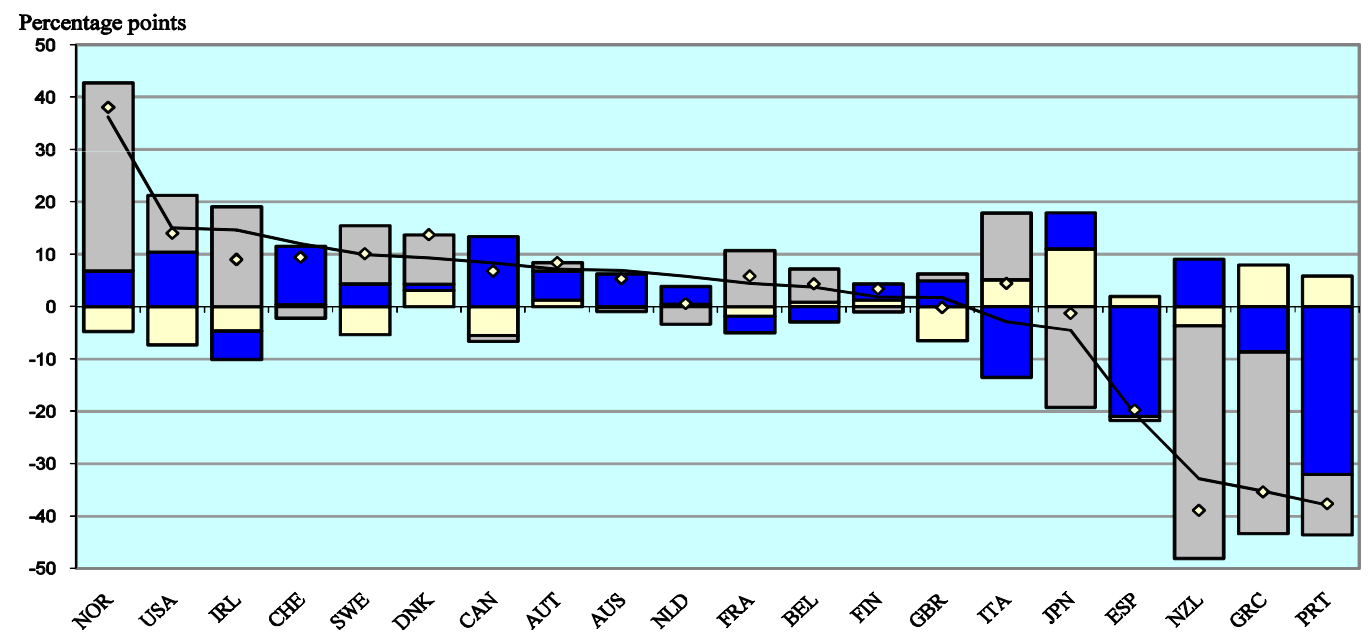

1. These charts show the contribution of each explanatory variable to GDP per capita based on Table 1. The contributions are computed as differences to the average country and on average over the period 2000-2004. The contribution of fixed effects is the sum of country and year fixed effects in Panel $A$, and the sum of country fixed effects and country specific time trends in the Panel B. For Norway and Panel A, as an example, the chart reads as following: On average between 2000-2004, Norway had a GDP per capita which was $36 \%$ above the average across countries, whereas the estimated difference to the average is $23 \%$ based on Table 1, column (1). These $23 \%$ are broken down according to the contribution of fixed effects (23\%), physical capital $(-3 \%)$ and human capital $(3 \%)$. Because of a break in the series due to the reunification, data for Germany were used only for the period 1970-1989. Therefore, Germany is not included in the figure.

9.

The sensitivity of human capital to the treatment of the time trend in either level or error-correction specifications can be partly explained by the fact that it is proxied by a variable (average number of years of schooling) that is characterised by a very smooth upward-trend profile over time. 
22. Figure 1 presents the contribution of physical capital, human capital and fixed effects to the gap in GDP per capita relative to the average OECD country and on average over the 2000-04 period. ${ }^{10}$ The results presented in the two panels are based on the specifications shown in column 1 and 4, respectively. Not surprisingly, the contribution of physical and human capital is small relative to that of the fixed effects. Indeed, the latter account for $72 \%$ and $87 \%$ of the GDP per capita variance (over this average period) for the level and the error correction specification respectively. Some of the highest fixed effects are in both specifications recorded for Norway and, to a lesser extent, the United States and Sweden. Portugal, Greece, New Zealand and Japan have the largest negative effects. The position of Ireland and Switzerland is particularly sensitive to whether common or country-specific time trends are introduced.

23. The rest of the paper investigates whether some of these large fixed effects can be accounted for by indicators of economic geography and, more generally, the extent to which such indicators can explain part of income levels which is not explained by the usual determinants.

\section{Economic distance}

24. In this section, different measures of proximity to markets or centrality are introduced and tested in the empirical analysis as potential determinants of GDP per capita. Some of them are simple measures based on GDP, country size, population and distances vis-à-vis other countries. The others are model-based measures derived from bilateral trade flows.

\subsection{Why proximity matters}

25. The role of geographic distance and the influence of neighbouring countries have largely been neglected in traditional growth theory which relies essentially on national characteristics, e.g. factor endowments and technological progress. Yet, the clustering of economic activities is a well-known phenomenon that raises questions about the extent to which the proximity to high-income neighbours matters for a country's own income. The development process might indeed be hindered in countries that are distant from centres of economic activities.

26. Distance can affect productivity and income levels through various channels, including trade, foreign investment and technology diffusion. There is ample evidence showing the importance of distance for trade and FDI flows (e.g. Nicoletti et al. 2003), as well as for technology spillovers (Keller, 2002). Furthermore, trade and FDI are obvious channels of knowledge spillovers (Eaton and Kortum, 1994 and 1996), which reinforces the impact of distance on productivity.

27. Focusing on the trade channel, distance directly raises transport and other trade costs and is an obstacle to both domestic and foreign trade. There are a number of inter-related ways through which this channel affects productivity. Greater proximity to world markets increases the opportunity to concentrate resources in activities of comparative advantage. It also encourages specialisation of firms that can attain efficient scale and more generally exploit increasing returns in specific fields of production. Moreover, stronger competition pressures force companies to use available inputs efficiently and encourage them to innovate and maintain a competitive advantage.

28. In addition to influencing GDP per capita via its impact on technical efficiency, distance can also affect external terms of trade. A relatively remote and sparsely populated country has to internalise transport costs into producer prices of tradeable goods in order to remain competitive in world markets or

10. In order to minimise the number of determinants shown separately on the graph, the contribution of population growth is lumped with that of physical capital and the contribution of fixed effects cover both year and fixed effects in the top panel and country fixed effects and time trend in the lower panel. 
otherwise suffer lower sales. Because, by definition, the factor prices of mobile factors tend to be equalised across locations, the costs of remoteness are born by the immobile factors, i.e. mostly labour in an international perspective. Indeed, even if technologies are the same everywhere, firms in more remote countries can only afford to pay relatively lower wages (Redding and Venables, 2004).

29. In addition to its direct impact on incomes, geography might have an influence through other factors such as physical or human capital. Returns to physical and human capital might be higher in countries having a better access to large markets (Redding and Scott, 2003). In turn, a high return to skills increases the incentive to invest. As regards human capital, Redding and Scott provide some evidence that the world's most peripheral countries have relatively low levels of education, a feature found also in the case of European regions (Breinlich, 2007).

\section{2. $\quad$ The distance of OECD countries to world markets}

30. In this section, four measures of proximity to markets or centrality are constructed and compared. The first one is population density. The second one depends solely on distances between countries. The third one is a simple measure based on distances vis-à-vis other countries and the size of their GDPs, and the last one is a model-based measure derived from bilateral trade flows. Section 4 is specifically dedicated to the effects of economic distance measured by transport costs.

\subsubsection{Population density, sum of distances and market potential}

31. Population density, defined as the ratio of population to surface area, is an indicator of proximity to the domestic market. The higher the density the lower the aggregated domestic transport costs. However, the critical shortcoming of this measure is its failure to take into account the effective access to foreign markets.

32. A simple measure of distance to markets that does so is one based on bilateral distances. From the perspective of empirical analysis, this measure is attractive because it is based on exogenous characteristics of geography. Although the sum of the distances of each country to Tokyo, Brussels and New York has been commonly used in the empirical literature, the choice of these three locations is arbitrary and creates issues of endogeneity.

33. Hence, a better alternative is to sum the distances to all countries (Head and Mayer, 2007):

$$
\operatorname{Distsum}_{i}=\sum_{j} d_{i j}
$$

In order to compute Distsum, the world was divided in 32 areas: Africa, Australia, Austria, Belgium, Brazil, Canada, China, CIS countries, Denmark, Eastern Europe, Finland, France, Germany, Greece, Ireland, Italy, Japan, Korea, Latin America (other than Brazil and Mexico), Mexico, the Middle East, the Netherlands, New Zealand, Norway, Portugal, Spain, Sweden, Switzerland, Turkey, the United Kingdom, the United States and Asia (other that the countries already included). Pure distance measures, however, fail to take into account the size of markets. Moreover, this measure depends on how geographic areas are constructed. For example, a different picture would be obtained if the European Union was considered as one entity or, alternatively, the North America was disaggregated into states / provinces.

34. Therefore, a more refined measure of proximity to markets is market potential, which is defined as the sum of all countries' GDP weighted by the inverse of the bilateral distance (Harris, 1954): 


$$
\text { Market Potential }_{i}=\sum_{j} \frac{G D P_{j}}{d_{i j}}
$$

The market potential measure must take into account, for a given country, the domestic market and include its own GDP weighted by the inverse of internal distance. Because the internal distance is generally smaller than external distances, it is associated with a greater weight and is therefore a sensitive parameter for measures of centrality. The most commonly used distance indicators combine geodesic capital-tocapital distances between countries and internal distances based on surface areas. ${ }^{11}$ It follows that market potential is likely to be positively correlated with population density due to the domestic component.

\subsubsection{Market and supplier access}

35. Although it is an intuitive indicator of centrality, market potential is an ad-hoc way of capturing the influence of distance to markets. In particular, the weighting of foreign markets in the market potential computation is based solely on distances, regardless of the true accessibility of these markets. In that respect, market potential is a very crude measure of market access. Indeed, accessibility depends, in addition to distance, on trade policy and cultural relationships, among other determinants. A better approach consists in looking not only at the potential, but rather at the actual accessibility to countries' markets.

\section{Box 1. Construction of market access and supplier access measures}

Market and supplier access measures are derived from the estimation of a gravity-like relationship. As is common in the literature, trade costs in the bilateral trade specification are assumed to depend on three variables: bilateral distance, common border and common language. Noting $X_{i \rightarrow j}$ as the export from country $i$ to country $j$ and $d_{i j}$ the bilateral distance, the following equation is estimated for each year $t$ :

$$
\log X_{i \rightarrow j, t}=s_{i t}+a_{t} \cdot \log d_{i j}+b_{t} . \text { Border }+c_{t} . \text { Language }+m_{j t}+v_{i j t}
$$

where the so-called freeness of trade $(\phi)$, which is inversely related to trade costs, is given by $\log \phi_{i j t}=a_{t} . \log d_{i j}+b_{t}$.Border $+c_{t}$.Language. The estimates of "intra-country" freeness of trade, $\phi_{i i t}$, are computed based on the same formula applied to internal distance, common border and common language. $s_{i t}$ and $m_{j t}$ are unobserved exporter and importer characteristics, respectively. For each year, they are proxied by country fixed effects. According to the model (see Boulhol and de Serres, 2008, for details), these effects capture some characteristics of the countries related to the number of varieties, expenditures on manufactures, price indices, etc. Market and supplier access, respectively $M A$ and $S A$, are then constructed from the estimated parameters of the bilateral equation according to:

$$
M A_{i t}=\sum_{k} m_{k t} \cdot \phi_{i k t} \quad ; \quad S A_{i t}=\sum_{k} s_{k t} \cdot \phi_{i k t}
$$

For all the countries, market access (supplier access respectively) is computed as a weighted sum of unobserved importer characteristics $m{ }_{j}$ (exporter characteristics $s_{i}$ respectively) of all countries. Only the weights put on each partner change across countries, with these weights being a function of estimated trade costs. If a given country $k$ has a large market capacity $m_{k}$, countries having low trade costs with country $k$, i.e. a high freeness of trade, put a high weight on $m_{k}$ and tend to have a high market access. A similar argument applies to supplier access for countries having low trade costs with partners having a large export capacity. Note that this is the same principle as that applied to market potential, whose computation boils down to weighting all countries' GDP by the inverse of the bilateral distances.

11. The underlying assumption behind the internal distance $d_{i i}=2 / 3 \sqrt{\text { area }_{i} / \pi}$ is that a country is a disk where all suppliers are located in the center and consumers are located uniformly over the area. An alternative measure consists in using the largest cities in each country both for external and internal distances. This entails some differences depending on the size of the countries. However, the results in this paper proved to be robust to the choice of the distance definition. 
36. A measure based on such an approach has been proposed in the new economic geography literature, which has revived the concept of proximity to markets and formalised the role of economic geography in determining income. Using the methodology proposed by Redding and Venables (2004) and described in Box 1, measures of market and supplier access have been derived from bilateral trade equations estimated over the period 1970 and 2005 for the 32 countries / areas covering $98.5 \%$ of world trade flows in goods (see Boulhol and de Serres, 2008, for details).

\subsubsection{Comparison of the different measures}

37. The various measures of centrality discussed in the previous sub-section have been computed for most OECD countries and Table 2 reports the computed values for 2005, plus the average of the country ranking over the different measures. To facilitate the comparison, each of these measures is scaled such that the average across countries is 100 for each year. The cross-country pattern is reasonably close across indicators. Linear correlation is especially high, at around 95\%, between market potential, market access and supplier access (and the average ranking). Ranking the countries enables to distinguish five groups, in ascending order and Figure 2 represents this clustering using market potential for illustration purposes:

- The remote and sparsely populated countries: Australia and New Zealand;

- Low-income peripheral countries;

- High-income peripheral countries, Korea and North America;

- Continental Europe, the United Kingdom and Japan;

- The centrally located and dense economies of Belgium and the Netherlands. 
Table 2. Measures of proximity/distance to markets, 2005

\begin{tabular}{|c|c|c|c|c|c|c|}
\hline \multicolumn{6}{|c|}{ Average across countries $=100$ for each indicator } & \multirow{2}{*}{$\begin{array}{l}\text { Average } \\
\text { ranking }\end{array}$} \\
\hline & $\begin{array}{c}\text { Sum of } \\
\text { distances } \\
\text { (Distsum) }\end{array}$ & $\begin{array}{c}\text { Market } \\
\text { potential }\end{array}$ & $\begin{array}{l}\text { Market } \\
\text { access }\end{array}$ & $\begin{array}{l}\text { Supplier } \\
\text { access }\end{array}$ & $\begin{array}{c}\text { Population } \\
\text { density }\end{array}$ & \\
\hline Australia & 214 & 21 & 25 & 23 & 2 & 1.4 \\
\hline Austria & 69 & 124 & 116 & 123 & 78 & 16.2 \\
\hline Belgium & 69 & 194 & 236 & 222 & 113 & 21.8 \\
\hline Canada & 113 & 111 & 126 & 86 & 3 & 10.6 \\
\hline Denmark & 68 & 136 & 119 & 130 & 97 & 18.0 \\
\hline Finland & 72 & 79 & 66 & 74 & 12 & 8.0 \\
\hline France & 70 & 153 & 145 & 137 & 84 & 18.2 \\
\hline Germany & 68 & 152 & 154 & 172 & 197 & 21.6 \\
\hline Greece & 76 & 70 & 61 & 55 & 63 & 7.2 \\
\hline Ireland & 73 & 107 & 100 & 101 & 46 & 11.8 \\
\hline Italy & 72 & 116 & 115 & 110 & 150 & 15.2 \\
\hline Japan & 139 & 127 & 111 & 163 & 266 & 15.6 \\
\hline Korea & 131 & 85 & 104 & 154 & 406 & 14.2 \\
\hline Mexico & 149 & 44 & 44 & 33 & 43 & 4.0 \\
\hline Netherlands & 69 & 183 & 221 & 199 & 308 & 22.8 \\
\hline New Zealand & 234 & 20 & 26 & 25 & 14 & 2.2 \\
\hline Norway & 70 & 93 & 76 & 80 & 11 & 9.8 \\
\hline Portugal & 81 & 76 & 73 & 59 & 90 & 8.4 \\
\hline Spain & 77 & 89 & 96 & 73 & 67 & 10.0 \\
\hline Sweden & 70 & 91 & 75 & 84 & 15 & 10.6 \\
\hline Switzerland & 70 & 144 & 136 & 147 & 143 & 18.8 \\
\hline Turkey & 78 & 60 & 52 & 52 & 75 & 6.6 \\
\hline United Kingdom & 70 & 169 & 158 & 136 & 189 & 19.4 \\
\hline United States & 119 & 82 & 92 & 64 & 27 & 7.6 \\
\hline \multicolumn{7}{|c|}{ Linear correlation coefficient } \\
\hline Sum of distances & & -0.69 & -0.57 & -0.52 & -0.17 & -0.62 \\
\hline Market potential & & & 0.96 & 0.92 & 0.50 & 0.97 \\
\hline Market access & & & & 0.93 & 0.53 & 0.92 \\
\hline Supplier access & & & & & 0.71 & 0.95 \\
\hline Density & & & & & & 0.62 \\
\hline
\end{tabular}

1. All the countries are ranked based on each of the five indicators, 1 standing for the most remote country and 24 for the most central one. The average ranking is the average of these five rankings. 
Figure 2. Market potential, $2005^{1}$

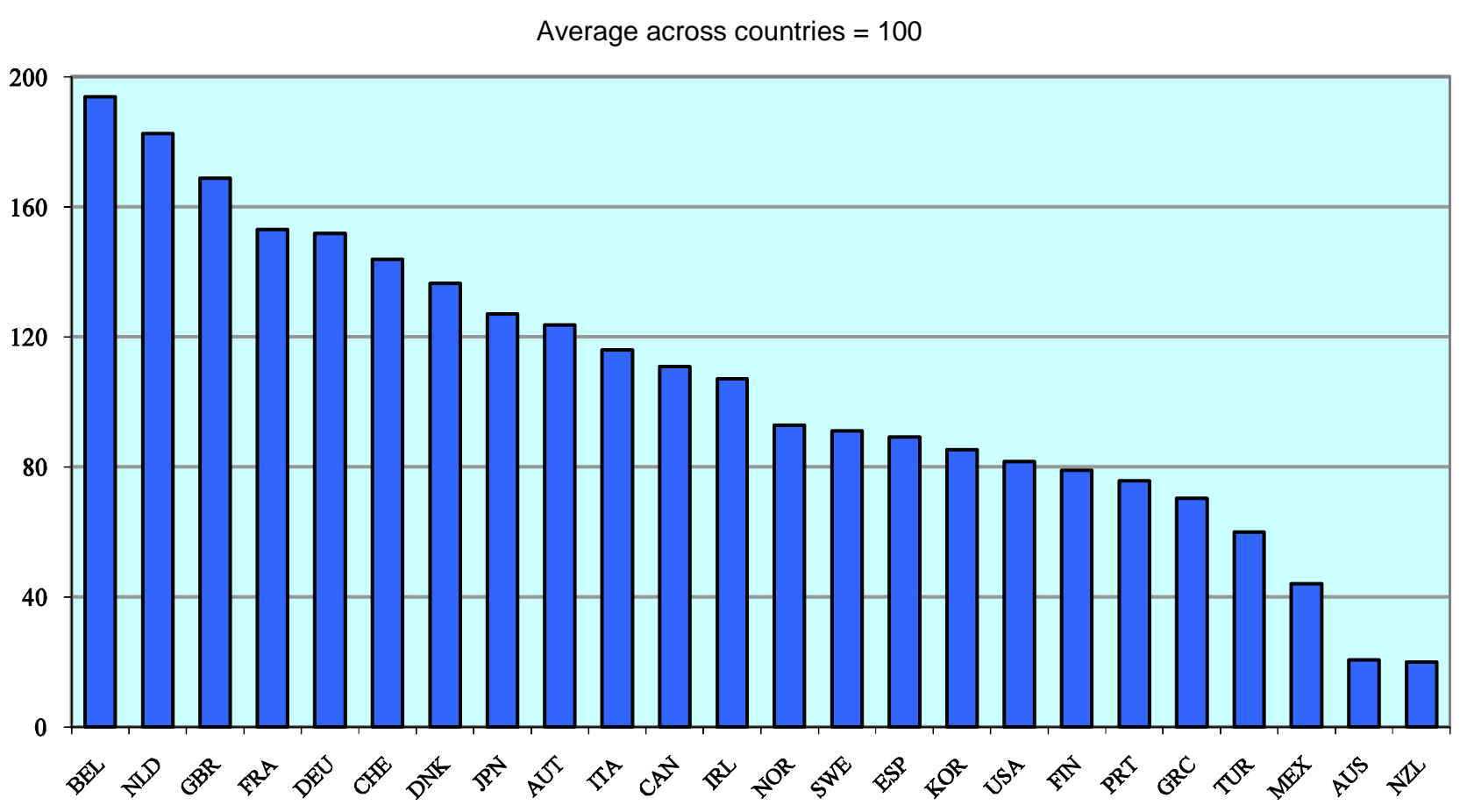

1. Market potential is defined in equation (4).

38. As expected, access measures are negatively correlated to the sum of distances and positively correlated to population density, suggesting that market and supplier access encompasses these different geographical dimensions. Besides, population density is an important factor explaining the position of Japan and Korea at or above what could be expected from the pure sum-of-distances measure. ${ }^{12}$

39. Given the size of its own market, the relative position of the United States in terms of market potential or market access might look surprising. As shown by the first column in Table 2 which gives the simplest measure of proximity, one reason is that the United States is much further from markets than European countries. Another reason is that the size of the domestic market is not in itself an adequate indicator of market potential or access to markets. To see this more closely, Table 3 breaks down market potential and market access into their domestic and foreign components, respectively. Looking for example at market potential, it is true that the domestic component represents two thirds of the total for the United States whereas that share is only $22 \%$ for the Netherlands and $4.5 \%$ for Canada. Still, the domestic market potential for the United States is only $30 \%$ greater than that for the Netherlands, even though its GDP is 20 times bigger. This is because the internal distance of the United States is fifteen times bigger. What matters is not the size of the total domestic market, captured here by the GDP, but that size relative to internal distance. ${ }^{13}$ In any case, these considerations have very limited consequences for the econometric analysis

12. When variables are compared in yearly changes over the whole panel rather than in levels, the correlation is still very significant, but falls to $50 \%$ and $36 \%$ between market potential, on the one hand, and market and supplier access, respectively, on the other hand.

13. In that context, the higher calculated total market potential for Canada than for the United States reflects the specific capital-to-capital measure of distance. Whereas the internal distance for the United States is $1,161 \mathrm{~km}$, the capital-to-capital distance between the two countries is $737 \mathrm{~km}$. Hence, this measure of distance gives the US GDP a greater weight for Canada than for the United States itself. This feature disappears when the distance measure takes into account not only the capital but also the biggest cities in each country (see Boulhol and de Serres, 2008). 
that follows, since they refer essentially to the levels of the proximity measures and most of the regressions include country fixed effects.

Table 3. Domestic and foreign components of market potential and market access, 2005

Base: "World" = 100

\begin{tabular}{|c|c|c|c|c|c|c|c|}
\hline & \multicolumn{3}{|c|}{ Market potential } & \multicolumn{3}{|c|}{ Market access } & \multirow{2}{*}{$\begin{array}{c}\text { Internal } \\
\text { distance }^{1} \\
\mathrm{Km}\end{array}$} \\
\hline & Total & Domestic & Foreign & Total & Domestic & Foreign & \\
\hline$\overline{\text { Australia }}$ & 21 & 4 & 17 & 25 & 9 & 17 & 1043 \\
\hline Austria & 124 & 14 & 110 & 116 & 13 & 103 & 109 \\
\hline Belgium & 194 & 27 & 166 & 236 & 69 & 167 & 68 \\
\hline Canada & 111 & 5 & 106 & 126 & 7 & 120 & 1188 \\
\hline Denmark & 136 & 17 & 120 & 119 & 16 & 103 & 78 \\
\hline Finland & 79 & 4 & 75 & 66 & 6 & 60 & 218 \\
\hline France & 153 & 39 & 114 & 145 & 32 & 113 & 278 \\
\hline Germany & 152 & 63 & 89 & 154 & 73 & 81 & 225 \\
\hline Greece & 70 & 8 & 62 & 61 & 9 & 52 & 136 \\
\hline Ireland & 107 & 10 & 97 & 100 & 12 & 88 & 100 \\
\hline Italy & 116 & 43 & 73 & 115 & 54 & 61 & 206 \\
\hline Japan & 127 & 99 & 28 & 111 & 83 & 28 & 231 \\
\hline Korea & 85 & 34 & 52 & 104 & 61 & 43 & 119 \\
\hline Mexico & 44 & 7 & 37 & 44 & 10 & 34 & 528 \\
\hline Netherlands & 183 & 41 & 142 & 221 & 96 & 126 & 77 \\
\hline New Zealand & 20 & 3 & 17 & 26 & 9 & 18 & 195 \\
\hline Norway & 93 & 7 & 86 & 76 & 6 & 70 & 214 \\
\hline Portugal & 76 & 8 & 68 & 73 & 12 & 62 & 114 \\
\hline Spain & 89 & 21 & 68 & 96 & 40 & 55 & 268 \\
\hline Sweden & 91 & 7 & 84 & 75 & 8 & 68 & 252 \\
\hline Switzerland & 144 & 24 & 120 & 136 & 19 & 117 & 76 \\
\hline Turkey & 60 & 6 & 54 & 52 & 6 & 46 & 332 \\
\hline United Kingdom & 169 & 60 & 109 & 158 & 65 & 93 & 186 \\
\hline United States & 82 & 54 & 28 & 92 & 64 & 28 & 1161 \\
\hline
\end{tabular}

1. The underlying assumption behind the internal distance $d_{i i}=2 / 3 \sqrt{\text { area } /} \pi$ is that a country is a disk where all suppliers are located in the centre and consumers are located uniformly over the area.

\subsection{Empirical analysis: Augmented Solow model and proximity}

40. The impact of access to markets on GDP per capita has been tested in different contexts and all these studies find that proximity has an important impact on GDP per capita. ${ }^{14}$ However, none of them has focused on developed countries despite their widely varying access to markets. In a broad sample covering

14. Redding and Venables apply their framework to a cross-section of 101 countries, while Breinlich (2007), highlighting that regional income levels in the European Union display a strong core-periphery gradient, tests the impact of market access using a panel of European regions over 1975-1997. Head and Mayer (2007) conduct a similar exercise based on European sectoral data over a shorter period. Concurrently, Hanson (2005) develops a model assuming labour mobility and tests it using data covering US counties. Combes and Overman (2004) present a survey of studies replicating Hanson's approach for various European countries. 
both least and most developed countries, Australia and New Zealand generally appear to have overcome the "tyranny of distance" (Dolman, Parham and Zheng, 2007). However, this inference might be misleading if the data do not enable to account for important country specificities. Focusing on a more homogenous group over a large period using panel techniques should therefore lead to a more reliable estimate.

41. This sub-section assesses the impact of the different measures of proximity/distance on GDP per capita when added to the usual explanatory variables in the augmented Solow framework. ${ }^{15}$ Table 4 presents a first set of results obtained from the GDP per capita level specification. In order to identify the sum-of-distances and population density measures, country fixed effects have to be removed and, therefore, the first two columns include country effects, whereas the last two do not. ${ }^{16}$ This first set of results indicates that the effect of proximity is robust to the various measures. Market potential, the weighted sum of market and supplier access, and the sum of distances are all highly significant with the expected sign, with only population density not having any strong link to GDP per capita. ${ }^{17}$ This confirms that, as expected from the previous section, population density is a much weaker indicator of proximity to markets than the other three. Based on the estimates related to the sum of distances (which do not control for country fixed effects), an increase of $10 \%$ in the distances to all countries triggers a decrease of $2.1 \%$ in GDP per capita. ${ }^{18}$

15. Based on a cross-section of 148 countries, an earlier study showed that proximity (market potential) explains a significant fraction of the income pattern even after controlling for the usual determinants in Solow-type regressions (Hummels, 1995).

16. As in Section 2 (Table 1), the human capital parameter is very sensitive to whether country fixed effects are included.

17. Due to the strong correlation between market and supplier access, the specific effect of each indicator cannot be identified. However, the explanatory variable in the model is a weighted sum of the two indicators, the weights being given by structural parameters; see Boulhol and de Serres (2008) for details.

18. This would imply, for example, that the relatively large distance of Australia from world markets compared with the United States accounts for a GDP-per-capita gap of around 12 percentage points (given the values of the sum-of-distances measure reported in Table $3,0.21 . \ln (214 / 119) \approx 0.12$ ). 
Table 4. Basic framework with proximity variables ${ }^{1}$

\begin{tabular}{|c|c|c|c|c|}
\hline $\begin{array}{l}\text { Dependant variable } \\
\text { GDP per capita }\end{array}$ & $\begin{array}{c}\text { level } \\
\text { AR (1) }\end{array}$ & $\begin{array}{c}\text { level } \\
\text { AR (1) }\end{array}$ & $\begin{array}{c}\text { level } \\
\text { AR (1) }\end{array}$ & $\begin{array}{c}\text { level } \\
\text { AR (1) }\end{array}$ \\
\hline & (1) & (2) & (3) & (4) \\
\hline \multirow[t]{2}{*}{ Physical capital } & $0.178 * * *$ & $0.174 * * *$ & $0.178 * * *$ & $0.156 * * *$ \\
\hline & $(0.020)$ & (0.019) & $(0.020)$ & $(0.024)$ \\
\hline \multirow{2}{*}{ Human capital } & $0.313^{* * *}$ & $0.317^{* * *}$ & $0.928 * * *$ & $0.813^{* * *}$ \\
\hline & $(0.115)$ & $(0.122)$ & $(0.070)$ & $(0.051)$ \\
\hline \multirow[t]{2}{*}{ Population growth ${ }^{2}$} & -0.003 & -0.005 & -0.006 & -0.014 \\
\hline & $(0.018)$ & $(0.018)$ & $(0.023)$ & $(0.028)$ \\
\hline \multirow[t]{2}{*}{ Market potential } & $0.086^{* * *}$ & & & \\
\hline & $(0.023)$ & & & \\
\hline Weighted sum market & & $0.056^{* * *}$ & & \\
\hline and supplier access & & $(0.015)$ & & \\
\hline \multirow[t]{2}{*}{ Sum of distances } & & & $-0.210 * * *$ & \\
\hline & & & $(0.023)$ & \\
\hline \multirow[t]{2}{*}{ Population density } & & & & 0.008 \\
\hline & & & & $(0.005)$ \\
\hline Rho $^{3}$ & 0.863 & 0.882 & 0.946 & 0.913 \\
\hline \multicolumn{5}{|l|}{ Fixed effects } \\
\hline Country & yes & yes & no & no \\
\hline Year & yes & yes & yes & yes \\
\hline \multicolumn{5}{|l|}{ Sample size } \\
\hline Total number of observations & 696 & 696 & 696 & 696 \\
\hline Number of countries & 21 & 21 & 21 & 21 \\
\hline
\end{tabular}

Note: Standard errors are in brackets. *: significant at $10 \%$ level; ** at $5 \%$ level; ${ }^{* * *}$ at $1 \%$ level.

1. The functional form corresponding to the "level" specification is reported in section 2.2. Standard errors are robust to heteroscedasticity and to contemporaneous correlation across panels.

2. The population growth variable is augmented by a constant factor $(g+d)$ designed to capture trend growth in technology and capital depreciation. This constant factor is set at 0.05 for all countries.

3. rho is the first-order auto-correlation parameter.

42. In order to test the robustness of the proximity effects across specifications, the following results focus on the indicator that rests more firmly on sound theoretical grounds, i.e. market and supplier access. The first three columns of Table 5 add the weighted sum of market and supplier access to the specifications shown in Columns 1 to 3 of Table 1, respectively. Market and supplier access is always highly significant, being robust to the inclusion of country and year dummies, as well as country specific time trends. Moreover, the estimate for the access variable is around 0.06-0.07 in all cases, while the parameters for human and physical capital are mostly unchanged compared with Table $1 .{ }^{19}$ This result suggests than the

19. These estimates are consistent with those shown in Boulhol and de Serres (2008) based on the pure Redding and Venables model in which market and supplier access are the only determinants of GDP per capita, once time and country fixed effects are controlled for. 
impact of centrality to markets acts on top of these usual determinants. Also, the fact that excluding the country effects does not alter the parameter significantly means that the access effect is identified by the variation through time as well as across countries.

Table 5. Sensitivity of proximity effects across specifications ${ }^{1}$

\begin{tabular}{|c|c|c|c|c|c|}
\hline $\begin{array}{l}\text { Dependant variable } \\
\text { GDP per capita }\end{array}$ & $\begin{array}{c}\text { level } \\
\text { AR (1) }\end{array}$ & $\begin{array}{c}\text { level } \\
\text { AR (1) }\end{array}$ & $\begin{array}{c}\text { level } \\
\text { AR (1) }\end{array}$ & $\begin{array}{c}\text { level } \\
\text { AR (1) } \\
\text { IV }\end{array}$ & \begin{tabular}{|c|}
$\begin{array}{c}\text { Error correction } \\
\text { model }\end{array}$ \\
PMG \\
\end{tabular} \\
\hline & $(1)$ & (2) & (3) & (4) & $(5)$ \\
\hline \multicolumn{6}{|l|}{ Common parameters } \\
\hline \multirow[t]{2}{*}{ Physical capital } & $0.174 * * *$ & $0.166^{* * *}$ & $0.188 * * *$ & $0.171^{* * *}$ & $0.307 * * *$ \\
\hline & $(0.019)$ & $(0.019)$ & $(0.017)$ & $(0.060)$ & $(0.032)$ \\
\hline \multirow[t]{2}{*}{ Human capital } & $0.317^{* * *}$ & $0.750 * * *$ & -0.069 & $0.855^{* * *}$ & $0.902 * * *$ \\
\hline & $(0.122)$ & $(0.075)$ & $(0.149)$ & $(0.208)$ & $(0.186)$ \\
\hline \multirow{2}{*}{ Population growth ${ }^{2}$} & -0.005 & -0.008 & -0.002 & 0.005 & $-0.411 * * *$ \\
\hline & $(0.018)$ & $(0.022)$ & $(0.018)$ & $(0.019)$ & $(0.067)$ \\
\hline Weighted sum of market & $0.056 * * *$ & $0.066^{* * *}$ & $0.064 * * *$ & $0.091^{* *}$ & $0.131^{* *}$ \\
\hline and supplier access & $(0.015)$ & (0.009) & $(0.016)$ & $(0.044)$ & $(0.054)$ \\
\hline $\mathrm{Rho}^{3}$ & 0.882 & 0.952 & 0.820 & 0.868 & \\
\hline \multicolumn{6}{|c|}{ Country-specific parameters } \\
\hline \multirow[t]{2}{*}{ Lambda $^{4}$} & & & & & $-0.176 * * *$ \\
\hline & & & & & $(0.024)$ \\
\hline Time trend & no & no & yes & no & yes \\
\hline \multicolumn{6}{|l|}{ Fixed effects } \\
\hline Country & yes & no & yes & yes & yes \\
\hline Year & yes & yes & yes & yes & no \\
\hline \multicolumn{6}{|l|}{ Sample size } \\
\hline Total number of observations & 696 & 696 & 696 & 696 & 695 \\
\hline Number of countries & 21 & 21 & 21 & 21 & 21 \\
\hline \multicolumn{6}{|l|}{ First stage regressions ${ }^{5}$} \\
\hline Hausman test & & & & $\begin{array}{l}\chi_{.}^{2}(4)=12.4 \\
(P=0.015)\end{array}$ & \\
\hline \multirow[t]{2}{*}{ Hansen J-stat } & & & & $\chi^{2}(29)=5.87$ & \\
\hline & & & & $(P$ value $=1.00)$ & \\
\hline \multirow[t]{2}{*}{ Physical capital } & & & & Shea $R^{2}=0.059$ & \\
\hline & & & & $(P$ value $=0.238)$ & \\
\hline \multirow[t]{2}{*}{ Human capital } & & & & Shea $R^{2}=0.182$ & \\
\hline & & & & $(P$ value $=0.000)$ & \\
\hline Weighted sum of market & & & & Shea $\mathrm{R}^{2}=0.092$ & \\
\hline and supplier access & & & & $(P$ value $=0.002)$ & \\
\hline
\end{tabular}

Note: Standard errors are in brackets. * : significant at $10 \%$ level; ${ }^{* *}$ at $5 \%$ level; ${ }^{* \star *}$ at $1 \%$ level.

1. The functional forms corresponding to the "level" and "error-correction" specifications are reported in section 2.2. In the level specification, standard errors are robust to heteroscedasticity and to contemporaneous correlation across panels. In the error-correction specification, only long term parameters are reported.

2. The population growth variable is augmented by a constant factor $(g+d)$ designed to capture trend growth in technology and capital depreciation. This constant factor is set at 0.05 for all countries.

3. rho is the first-order auto-correlation parameter.

4. The parameter lambda is the average of the country-specific speed adjustment parameter, $\lambda \mathrm{i}$.

5. The instruments used in column (4) are $Z_{i t}=$ Distsum $_{i} h_{t}$ where the $h_{t}$ are time dummies. The tests reported for the Instrumental Variables estimator read as following. The Hausman test is a joint test of exogeneity of physical capital, human capital and market and supplier access. Exogeneity is rejected and this is due to human capital only (this is seen when including residuals from the first-stage regressions in the main equation). The over-identification test is the Hansen test. It is computed without the AR(1) process for the residuals. For first-stage regressions, Shea partial $\mathrm{R}^{2}$ (i.e. based on the excluded instruments only) are reported for each potentially endogenous regressor, along with the $\mathrm{P}$-value of the F-test. These statistics reveal that weak instruments could be an issue for physical capital only. 
43. The estimated effect of access is fairly robust to the treatment of physical capital, human capital and the access variables as being potentially endogenous (column 4 ) ${ }^{20}$ Finally, in the last column, the error correction specification is tested using the pooled mean group estimator. Here again, the impact of centrality seems to be orthogonal to the other dimensions, although the level of the parameter is somewhat higher.

44. Figure 3 presents the contribution of market and supplier access to GDP per capita for the 20002004 period, based on the estimates in columns (1) and (5), which are representative of the level and errorcorrection specifications respectively. Unsurprisingly, Australia and New Zealand are the big losers from their geographic position. To a lesser extent, Greece, Portugal and Finland suffer compared to the average country. The beneficiaries are core European countries, especially Belgium and the Netherlands. As noted above, the order of magnitude of the geography effects varies substantially depending on the specifications. For example, market and supplier access is estimated to penalise Australia and New Zealand by around $11 \%$ of GDP in the level specification. The effect would be almost three times as large based on the error-correction specification, which is hardly plausible. Conversely, Belgium and the Netherlands benefit by around 6\%-7\% compared to the average country in the level framework and by $16 \%-18 \%$ in the error correction one.

Figure 3. Estimated impact of market and supplier access on GDP per capita ${ }^{1}$

Deviation from average OECD country in 2000-04

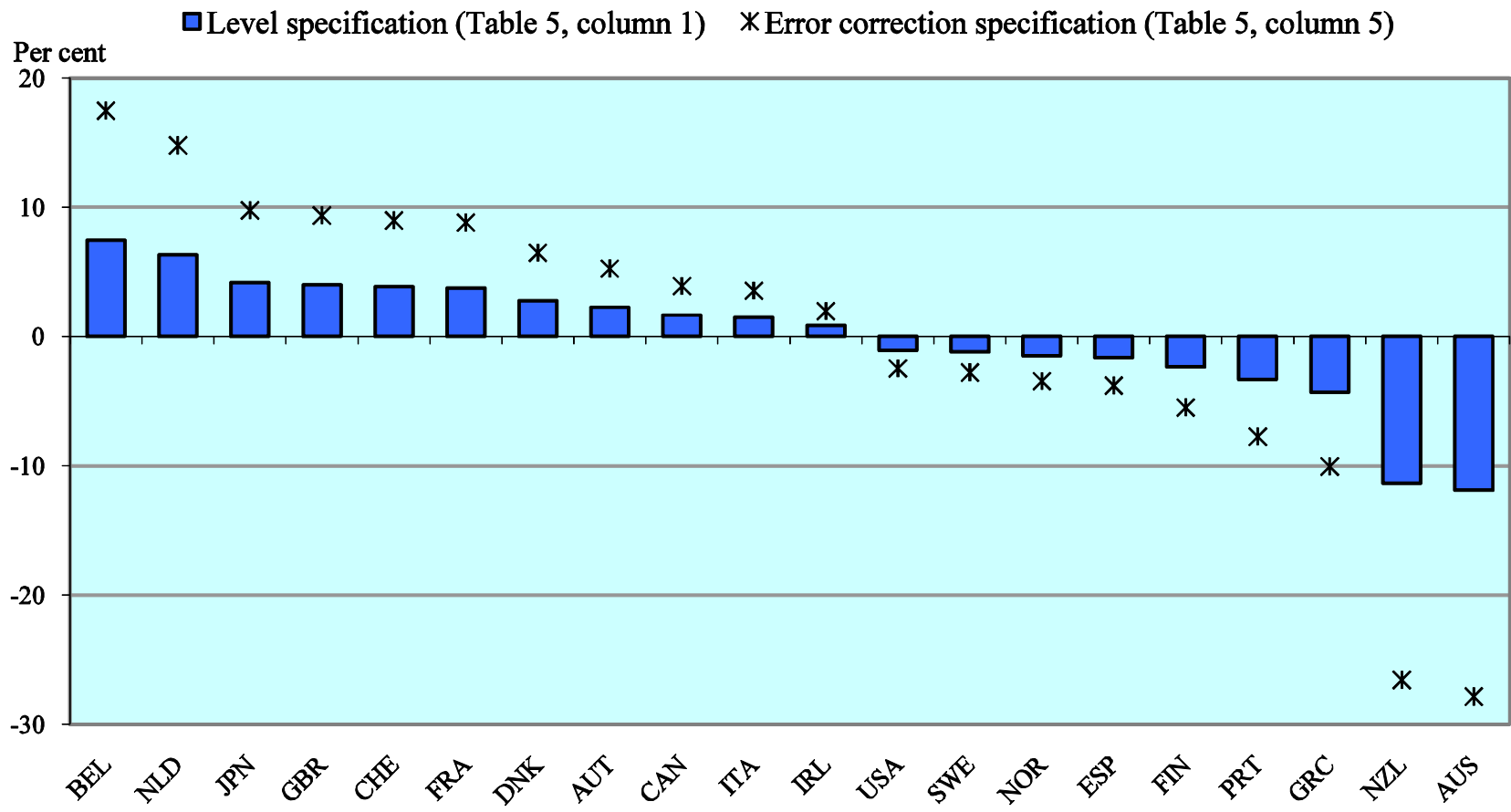

1. Contributions of market and supplier access to GDP per capita are based on Table 5. They are computed as differences to the average country and on average over the period 2000-2004. For example, based on the estimate from the level specification, the favourable access to world markets that Belgium benefits from compared with the average country would contribute to as much as $6.7 \%$ of its GDP. Because of a break in the series due to the reunification, data for Germany were used only for the period 1970-1989. Therefore, Germany is not included in the figure.

20. In order to try to overcome the potential endogeneity bias, the sum of distances variable, Distsum is an ideal instrument. Taking advantage of the panel dimension of the data, the effect of this time-invariant instrument is allowed to vary through time. In other words, a set of instruments, $Z_{i t}=$ Distsum $_{i} \cdot h_{t}$, are used where the $h_{t}$ are time dummies. 


\section{Transport costs}

45. In this section, the influence of proximity to large markets on GDP per capita is examined through the working of a direct channel: transportation costs. The cost of transporting goods is obviously closely linked to distance. However, shifts in modes of transport, technological improvements in longdistance shipping and changes in fuel costs have influenced the relationship between geographic distance and economic distance. To some extent, the impact of transport costs was implicitly captured in the measures of market and supplier access derived in the previous section. Nevertheless, the development of indicators of transport costs allows for assessing directly their impact on trade and GDP per capita, separately from other factors affecting market access, such as variations in the degree of openness to trade across various foreign markets as well as over time.

46. Transport costs constitute only one source of total trade costs, albeit an important one. According to recent estimates, broadly defined trade costs of "representative" goods expressed in ad valorem taxequivalent terms can be as high as 170\% in industrialised countries (Anderson and van Wincoop, 2004) with transport costs amounting to $21 \%$, the rest being accounted for by border-related trade barriers (44\%) and retail and wholesale distribution costs $(55 \%) .{ }^{21}$ Excluding distribution, transport costs would on the basis on these estimates account for about one-third of international trade costs. This covers the contribution of both direct (freight charges including insurance) and indirect (holding cost for transit, inventory costs, etc.) transport costs. The empirical analysis presented in this section is based on estimates of freight charges for air, maritime and road transportation of merchandise. Indirect costs, which are usually inferred from trade flow regressions rather than directly observed, are not covered. In addition, the cost of international telecommunications is considered insofar as it affects trade in services and, to a lesser extent, trade in goods via its impact on back-office operation, financing, etc.

47. The rest of the section provides some details on the construction of an index of overall transport costs and its three main components, as well as the cost of international telecommunications, for the 21 OECD countries included in the empirical analysis reported in the previous sections. Given the limited availability of data covering both the time-series and cross-section dimensions in a consistent and comparable fashion, a number of key assumptions are required in order to build a comprehensive dataset. The impact of transport costs on GDP per capita is then examined both via its impact on exposure to crossborder trade and directly as an added determinant in the basic framework used in earlier sections.

\subsection{Evolution of transport and telecommunications cost indices}

\subsubsection{Methodology and data sources}

48. The construction of an aggregate index of transportation costs covering air, maritime and road components requires information about the costs for shipping goods between bilateral locations for each mode of transport, with the respective costs measured in the same units to allow for aggregation. In addition, the construction of country-specific indices requires that the respective costs be weighted so as to reflect the relative importance of each trading partner as well as of each mode of transport. In principle, trade flow data could be used to construct weights that are consistent with the actual distribution of goods shipped according to the mode of transport and bilateral destinations. Doing so, however, would make the aggregate index endogenous to the individual costs and is therefore avoided. The indicators of transportation costs used in this paper are taken directly from Golub and Tomasik (2008), which provides

21. The overall cost is computed as $1.21 * 1.44 * 1.55-1=1.7$. Border-related costs include policy barriers (tariffs and non-tariffs), information and enforcement costs, as well as costs due to the use of different currencies, rules and legal frameworks. 
details regarding raw data availability, sources, assumptions made and results. The main features can be summarised as follows:

- The basic cost of each mode of transportation between any two locations is measured in US dollars per kilogramme shipped, and the cost of maritime shipping is assumed to be the same for countries within a broad region (e.g. for all EU countries vis-à-vis other broad regions).

- For each country, the costs of shipping goods to each bilateral destination are aggregated on the basis of GDP weights of partner countries (including a country's own GDP), as was the case for the indicator of market potential discussed in the previous section. The main reason for preferring GDP weights as opposed to actual trade weights is to avoid the endogeneity of trade patterns with respect to trade costs.

- The relative importance of each mode of transport in moving goods across locations is based on a mixture of assumptions and hard data that are available for a few countries. The key assumption made in this context is that all trade between "neighbours" is assumed to take place via road transportation.

- The nominal aggregate index of transport cost, expressed in dollars per kilogramme, is deflated using either the US GDP deflator or the US price index of manufacturing goods.

\subsubsection{Results}

49. The overall indicator of transport costs over the period 2000-2004 is shown in Figure 4 for 21 OECD countries. The figure also provides the contribution of each of the three main sub-components to the overall cost. Individual countries can be regrouped into four blocks on the basis of their overall costs. Not surprisingly, transport cost is highest for Australia and New Zealand with a cost over $2 \frac{1}{2}$ times that observed in North America. This is followed by Japan which forms a group on its own, but at a level that is substantially lower than observed for the first group. The indicator shows similar costs for European countries, with only slightly higher values observed in peripheral countries, reflecting higher road transport costs. At the other end, transport costs are lowest in Canada and the United States, owing largely to a lower contribution from maritime freight charges. In fact, the maritime component accounts for the largest portion of the variation in the overall costs across the four groups of countries. 
Figure 4. Overall transport costs and contribution from three sub-components

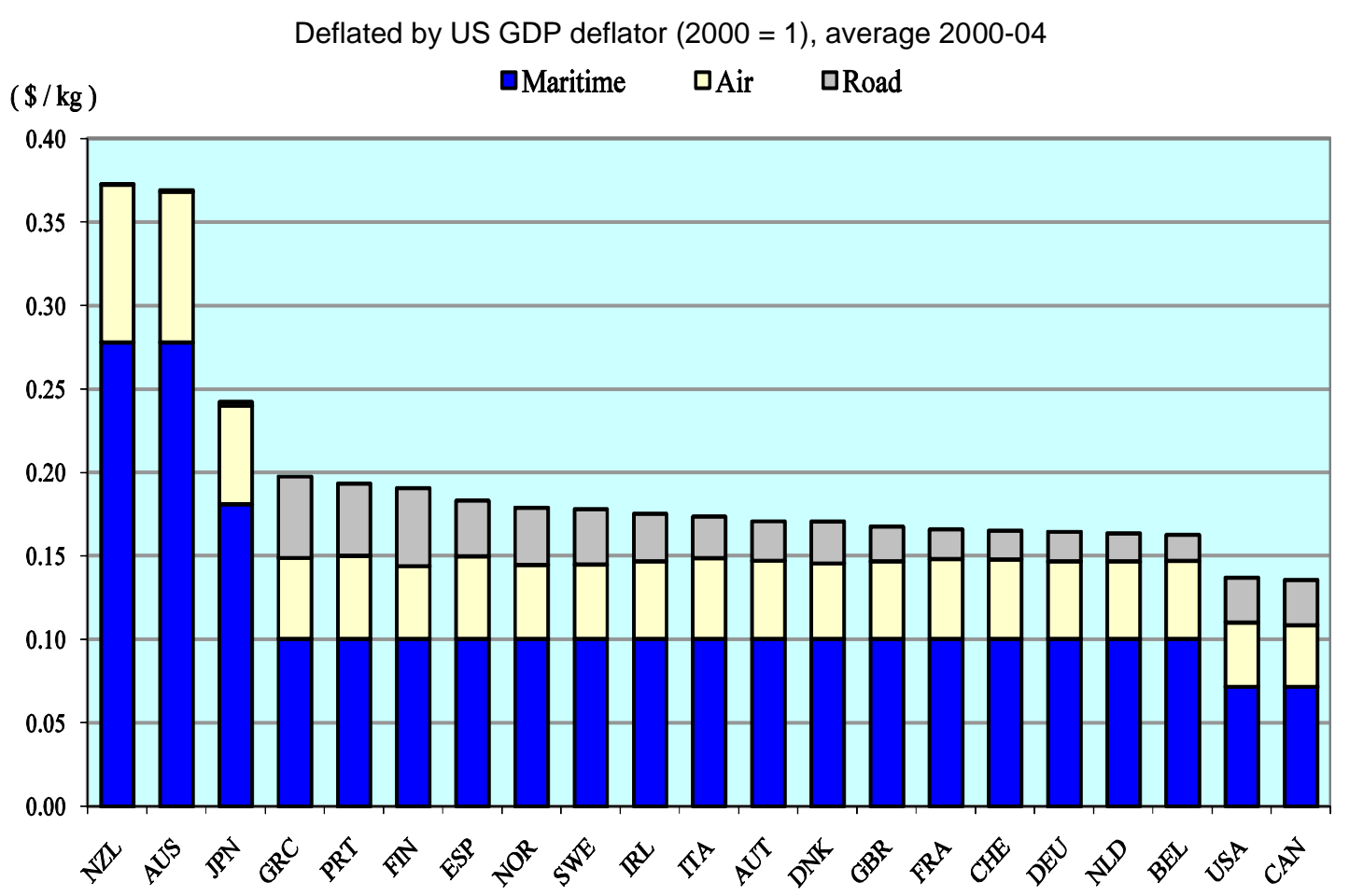

Source: Golub and Tomasik (2008).

50. As regards the evolution of overall transport costs over time, a different picture emerges depending on whether the series are deflated by the US GDP deflator or by the US price index of manufacturing goods. On the latter basis, there is a clear upward trend in the four groups of countries throughout the sample period -- though with somewhat different slopes - whereas no clear trend appears for the series based on the broader deflator, at least not since the 1970s (Figure 5). In both cases, the profile reflects to a large extent the contribution from maritime shipping costs (Figure 6). Looking more closely at the profile of maritime transport costs what stands out is the widening discrepancy since the mid-1990s between the cost for shipping goods from Asia, which have gone up in real terms, and those for goods shipped from Europe or North America, which have fallen. The break from the earlier pattern which saw the costs in the three zones moving roughly together coincides with the emergence of large trade imbalances. The sharp rise in exports from East Asia has led to capacity bottlenecks in the major ports of that region while containers are returned to Asia half empty. 
Figure 5. Total average transport cost

Europe ----USA and Canada - Australia and New Zealand Japan
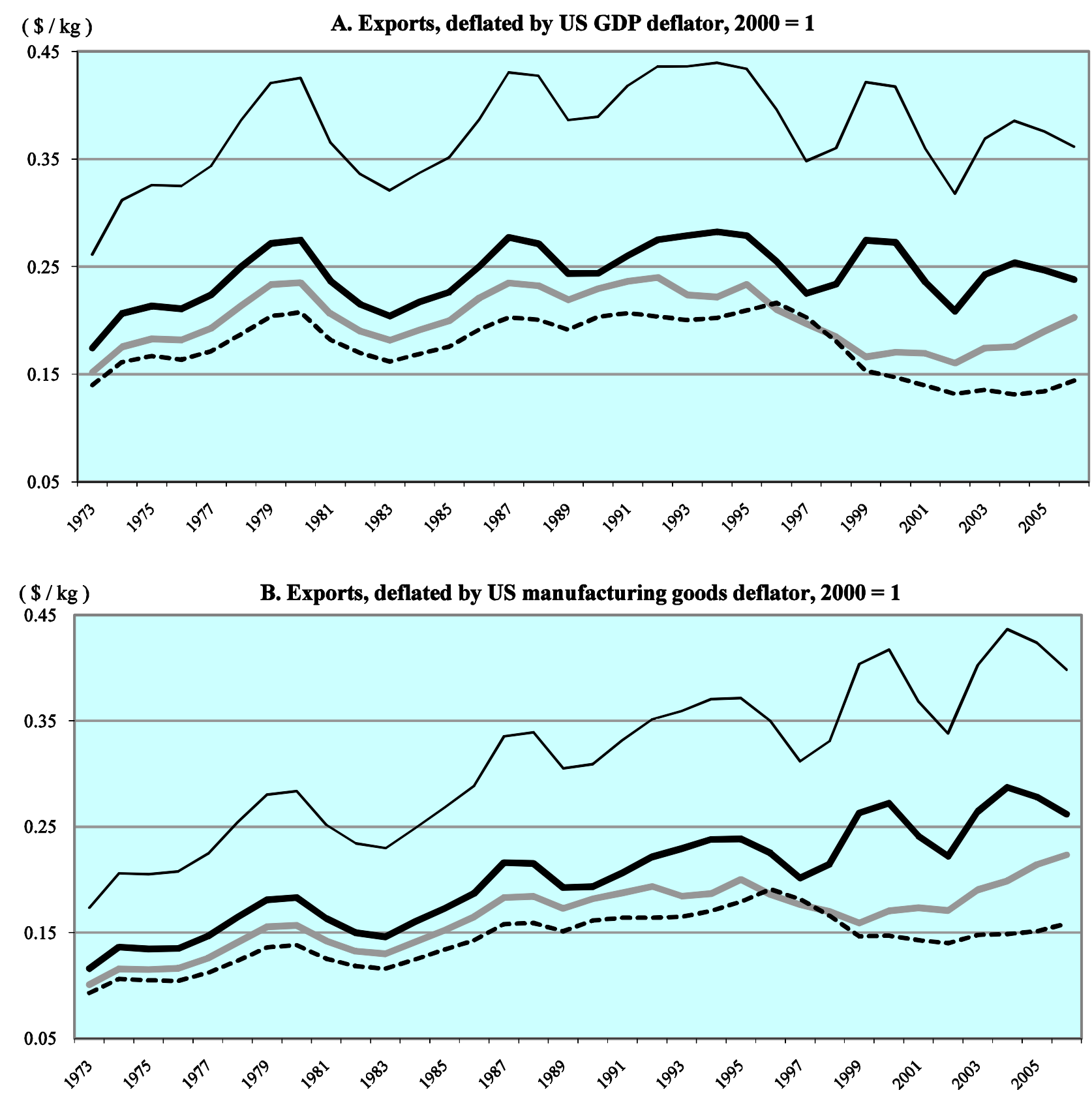

Source: Golub and Tomasik (2008). 
Figure 6. Average maritime transport cost
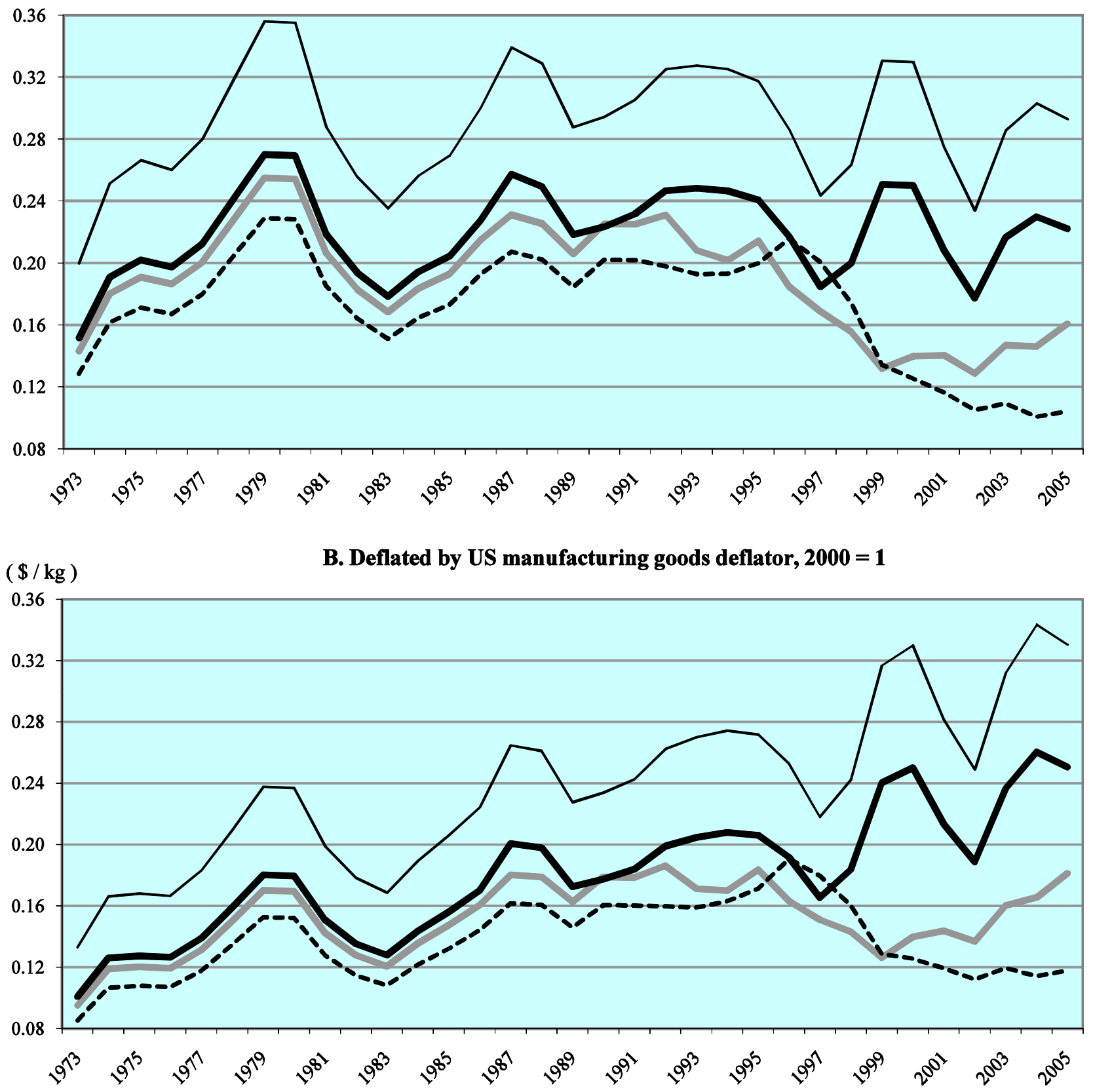

Source: Golub and Tomasik (2008). 
51. To summarise, the perception that the relative influence of costs related to distance is fast diminishing is not supported, at least not by recent trends in international shipping costs. ${ }^{22}$ This apparent puzzle was already noted in earlier studies (in particular Hummels, 2006). In the case of maritime transport, special factors such as rising fuel prices and port charges may have played a role in offsetting the gains from technological improvements. Moreover, studies based on micro data (Blonigen and Wilson, 2006) that compare prices for shipping similar goods and similar maritime routes but via different modes (i.e. using containers or not), suggest that the benefit from containerisation may not be as large as presumed (all else being equal).

52. In any case, firm conclusions in this area need to be qualified due to limitations of data availability and measurement. It is not clear how data on road transport, for instance, reflect the gains in quality terms such as those from the use of global positioning systems which allows for precise tracking of the material in transit. In a similar vein, measured price indices for ocean shipping may not adequately reflect improvement in the service provided, for instance time savings brought about by containerisation. And, the importance of time as a trade barrier has been stressed in earlier studies (Hummels, 2001; Nordås, 2006; Nordås et al., 2006). More generally, all transportation modes have benefited from progress in information and communication technology as well as from a better integration via intermodal systems. Taken at face value, the absence of a decline in the weight-based measures of real cost of transport (i.e. nominal costs deflated by the manufacturing price index) suggests that there may have been less technological progress in transportation than in manufacturing. However, due to innovations outside the transport sector, the composition of traded goods has changed significantly over the past decades, and many valuable goods are now relatively light, e.g. electronic chips. Consequently, transport costs may well have fallen relative to the value of transported goods. ${ }^{23}$

53. One area where the presumed death of distance does not seem to be at all exaggerated is international telecommunications since costs in this area have fallen in all countries to the point where they are no longer significant anywhere (Figure 7). In fact, historical data indicate that the substantial crosscountry variations that still prevailed in the early 1970s had largely disappeared by the late 1980s, and since then the downward trend has continued, bringing costs to basically zero during the early 2000s. It should be noted, however, that this indicator only captures one type of telecommunications and therefore the treatment of this aspect of distance is covered too narrowly for firm conclusions to be drawn. ${ }^{24}$

22. A clear downward trend in the relative price of merchandise transportation appears in the case of air transport, but only if the series is deflated by the GDP deflator rather than the narrower index of manufacturing goods prices.

According to Hummels (2007), the weight/value ratio of traded goods has fallen especially for the United States, since the early 1990s: one dollar (in real terms) of traded merchandise weighs much less today than in the 1970s. Hummels reports that the real value of trade grew 1.5 per cent per year faster than its weight since 1973. Because the measures above refer to the costs in dollar per $\mathrm{kg}$, and have been constructed on the basis of an unchanged weight/value ratio over time, they underestimate relative the decline in $a d$ valorem transport costs.

24. For telecommunications, an alternative approach would have been to look at measures of "distance" such as, for instance, the total outbound international network capacity in each country, either in absolute or per inhabitant. Unfortunately, such measures are typically not available before the 1990s. 
Figure 7. Real cost of one minute international telephone call from selected origin countries

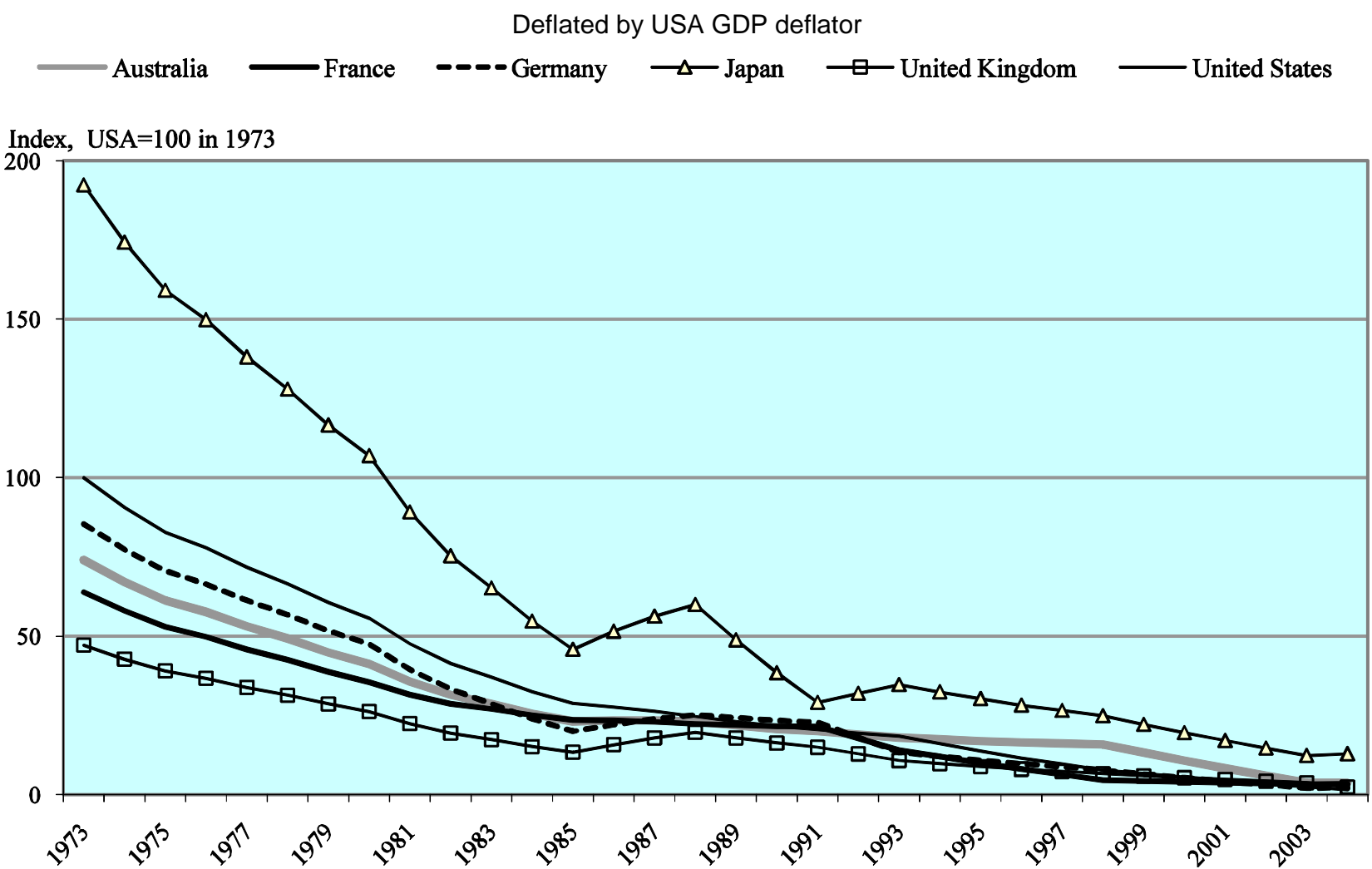

Source: Golub and Tomasik (2008)

\subsection{Impact of transport costs on openness to trade and GDP per capita}

54. The impact of transport costs on GDP per capita is assessed indirectly via their effects on individual countries' exposure to international trade (Table 6). This approach is based on the presumption that transportation costs matter for GDP per capita only insofar as they matter for openness and that trade contributes to GDP. In order to assess the contribution of international trade to GDP per capita, a measure of exposure to international trade (trade openness) is first added as a determinant in the augmented-Solow model. $^{25}$

25. Trade openness is measured as the average of export and import intensities (i.e. as a ratio of GDP) and is adjusted for country size. The adjustment is made by regressing the raw trade openness variable on population size and by taking the estimated residual from that panel regression as the measure of trade exposure that is included as an additional determinant in the augmented Solow specification. 
Table 6. Basic framework with openness to trade ${ }^{1}$

(Costs of transport and international communications used as an instrument for trade openness)

\begin{tabular}{|c|c|c|c|c|c|c|}
\hline $\begin{array}{l}\text { Dependant variable } \\
\text { GDP per capita }\end{array}$ & $\begin{array}{c}\text { level } \\
\text { AR (1) }\end{array}$ & $\begin{array}{c}\text { level } \\
\text { AR (1) } \\
\text { IV }\end{array}$ & $\begin{array}{c}\text { level } \\
A R(1)\end{array}$ & $\begin{array}{c}\text { level } \\
\text { AR (1) } \\
\text { IV }\end{array}$ & $\begin{array}{c}\text { level } \\
\text { AR (1) }\end{array}$ & $\begin{array}{c}\text { level } \\
\text { AR (1) } \\
\text { IV }\end{array}$ \\
\hline & (1) & (2) & (3) & (4) & (5) & (6) \\
\hline \multirow[t]{2}{*}{ Physical capital } & $0.175^{* * *}$ & $0.171 * * *$ & $0.164 * * *$ & $0.218 * * *$ & $0.208 * * *$ & $0.196 * * *$ \\
\hline & $(0.020)$ & $(0.022)$ & $(0.023)$ & $(0.030)$ & $(0.021)$ & $(0.022)$ \\
\hline \multirow[t]{2}{*}{ Human capital } & $0.234^{*}$ & -0.273 & $0.740 * * *$ & $0.724 * * *$ & $0.210^{*}$ & $0.221 * *$ \\
\hline & $(0.122)$ & $(0.324)$ & $(0.058)$ & $(0.068)$ & $(0.112)$ & $(0.112)$ \\
\hline \multirow[t]{2}{*}{ Population growth ${ }^{2}$} & -0.016 & -0.018 & -0.038 & -0.033 & -0.028 & $-0.044^{*}$ \\
\hline & $(0.023)$ & $(0.025)$ & $(0.031)$ & $(0.029)$ & $(0.025)$ & $(0.026)$ \\
\hline \multirow[t]{2}{*}{ Trade openness } & $0.035^{*}$ & 0.029 & $0.048 * * *$ & $0.107 * * *$ & $0.068 * * *$ & $0.106^{* * *}$ \\
\hline & $(0.020)$ & $(0.061)$ & $(0.017)$ & $(0.040)$ & $(0.020)$ & $(0.039)$ \\
\hline $\mathrm{Rho}^{3}$ & 0.886 & 0.890 & 0.941 & 0.954 & 0.844 & 0.855 \\
\hline Time trend & no & no & no & no & yes & yes \\
\hline \multicolumn{7}{|l|}{ Fixed effects } \\
\hline Country & yes & yes & no & no & yes & yes \\
\hline Year & yes & yes & yes & yes & no & no \\
\hline \multicolumn{7}{|l|}{ Sample size } \\
\hline Total number of observations & 633 & 633 & 633 & 633 & 633 & 633 \\
\hline Number of countries & 21 & 21 & 21 & 21 & 21 & 21 \\
\hline
\end{tabular}

First stage regressions for the Trade openness variable ${ }^{4}$

Excluded instruments

\begin{tabular}{|c|c|c|c|}
\hline Overall transport costs & $-0.473 * *$ & $-0.683 * * *$ & $-0.144 * *$ \\
\hline & $(0.233)$ & $(0.065)$ & $(0.062)$ \\
\hline Costs of international & 0.023 & $-0.148 * * *$ & -0.009 \\
\hline communications & $(0.024)$ & $(0.030)$ & $(0.027)$ \\
\hline Sum of distances & $-0.018 * * *$ & $-0.004 * *$ & $-0.027 * * *$ \\
\hline (average through time) & $(0.004)$ & $(0.002)$ & $(0.002)$ \\
\hline \multicolumn{4}{|l|}{ Statistical tests } \\
\hline \multirow[t]{2}{*}{ Hausman test } & $\chi^{2}(1)=2.76$ & $\chi^{2}(1)=3.57$ & $\chi^{2}(1)=5.10$ \\
\hline & $(P=0.096)$ & $(P=0.059)$ & $(P=0.024)$ \\
\hline \multirow[t]{2}{*}{ Hansen J-stat } & $\chi^{2}(31)=23.8$ & $\chi^{2}(31)=10.3$ & $\chi^{2}(31)=31.2$ \\
\hline & $(P$ value $=0.820)$ & $(P$ value $=1.000)$ & $(P$ value $=0.458)$ \\
\hline \multirow[t]{2}{*}{ Partial $\mathrm{R}^{2}$} & Shea $R^{2}=0.062$ & Shea $R^{2}=0.152$ & Shea $R^{2}=0.190$ \\
\hline & $(P$ value $=0.917)$ & $(P$ value $=0.000)$ & $(P$ value $=0.000)$ \\
\hline
\end{tabular}

Note: Standard errors are in brackets. *: significant at $10 \%$ level; ${ }^{* *}$ at $5 \%$ level; ${ }^{* \star *}$ at $1 \%$ level.

1. The functional form corresponding to the "level" specification is reported in section 2.2. Standard errors are robust to heteroscedasticity and to contemporaneous correlation across panels.

2. The population growth variable is augmented by a constant factor $(g+d)$ designed to capture trend growth in technology and capital depreciation. This constant factor is set at 0.05 for all countries.

3. rho is the first-order auto-correlation parameter.

4. The instruments used in column (2), (4) and (6) are overall transport costs, costs of international communications and $Z_{i t}=$ Distsum $_{i} h_{\mathrm{t}}$ where the $h_{\mathrm{t}}$ are time dummies. The tests reported for the Instrumental Variables estimator read as following. The Hausman test is a test of exogeneity of the trade variable. The over-identification test is the Hansen test. It is computed without the $A R(1)$ process for the residuals. For first-stage regressions, Shea partial $\mathrm{R}^{2}$ (i.e. based on the excluded instruments only) is reported for the potentially endogenous regressor, along with the $\mathrm{P}$-value of the F-test. 
55. The results appear in columns 1,3 and 5 of Table 6 , where the specifications vary only according to the combination of fixed-effects and/or time trend included. The coefficient on trade openness is positive and significant in all three cases - albeit only at the $10 \%$ level in the first case -- and varies from 0.035 when both year and country fixed-effects are included (column 1) to twice that size when a time trend is included instead of year fixed-effects (column 5). The coefficients on the other variables do not vary much across specifications, except in the case of human capital, where the coefficient shows the same sensitivity to the treatment of fixed effects as reported in previous sections. A comparison of Table 6 with the first three columns of Table 1 also shows that adding the trade variable does not have much impact on the parameter values of physical and human capital.

56. Taken at face value, these results provide evidence that greater openness to trade leads to higher GDP per capita. However, it has long been recognised that given the uncertainties as regards the direction of causality, the introduction of trade as an additional determinant in the Solow model cannot be used as conclusive evidence of a positive influence on GDP per capita, regardless of the apparent size and statistical significance of the estimated parameter.

57. To address the endogeneity problem, an instrumental variable (IV) procedure is adopted, allowing for the indicator of overall transport costs and the cost of international telecommunications to be used as instruments for the measure of openness to international trade in the augmented Solow model. The sum of distance, defined in the previous section, is also used as an instrument. ${ }^{26}$ The procedure is similar to that used in Section 3 and the results are reported in columns 2, 4 and 6 of Table 6 . The estimated effect of (instrumented) trade openness on GDP per capita (second stage reported in the top panel) is significant in two of the three specifications (columns 4 and 6), and the estimated coefficient is in these cases higher than when actual trade openness is used (columns 3 and 5). However, this result no longer holds if one controls for both country and year fixed effects, where the coefficient on trade openness is not significant (column 2) ${ }^{27}$ As for the results from the first-stage regression (bottom panel), they show that overall transport costs have a significant (negative) impact on trade openness in all three IV specifications, although with large variations in the parameter estimates.

58. Overall, these results indicate that transportation costs contribute to reduce the exposure to international trade and that in turn the latter appears to have a significant impact on GDP per capita. In contrast, the effect of international telecommunications on trade openness is significant only when country fixed effects are not included, and therefore the evidence is much weaker. The results from the IV procedure provides some evidence that trade openness may have a causal influence on GDP per capita, consistent with earlier findings (e.g. Frankel and Romer, 1999).

59. Against this background, the contribution of transport costs to GDP per capita is reported in Figure 8. In order to provide a range of estimates, the contribution is calculated on the basis of coefficients obtained from two specifications based on Table 6 (Columns 4 and 6, respectively). On this basis, high transport costs relative to the OECD average are found to reduce GDP per capita by between $1.0 \%$ and 4.5\% in Australia and New Zealand, where the effect is largest. At the other end, the lower transport costs for Canada and the United States contribute to raise GDP per capita by between $0.5 \%$ and $2.5 \%$.

26. Even though the variable does not have a time-series dimension, its estimated impact is allowed to vary over time. The value reported in the bottom panel of Table 6 , is the average of all parameter estimates.

27. The statistical tests reported at the bottom of Table 6 indicate that when both year and country fixed-effects are included (column 2), the instruments add little information and are therefore considered as weak. 
Figure 8. Estimated impact of transportation costs on GDP per capita ${ }^{1}$

Deviation from average OECD country in 2000-04

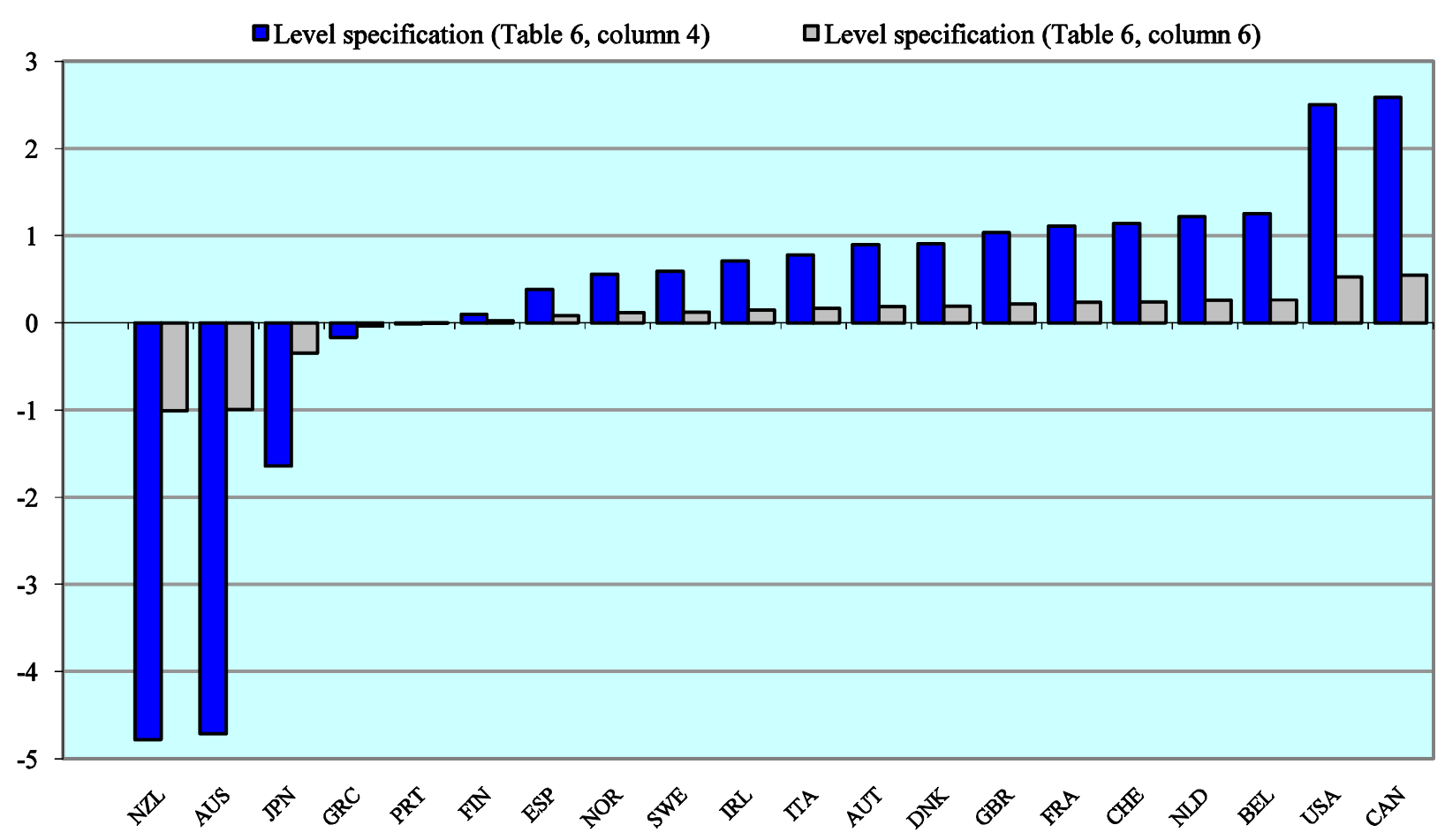

1. Contributions of market and supplier access to GDP per capita are based on Table 6. They are computed as differences to the average country and on average over the period 2000-04. Because of a break in the series due to the reunification, data for Germany were used only for the period 1970-1989. Therefore, Germany is not included in the figure.

\section{Natural resources and GDP per capita}

60. This section examines the impact of natural resource endowments on GDP per capita. The next sub-section briefly reviews the channels via which natural resources can have an impact on growth. This is followed by a discussion of the various measures used as proxies for natural resource endowments and the presentation of empirical results on the impact of resources on GDP per capita.

\subsection{Impact of resource endowments on growth: the main channels}

61. In principle, given the importance of raw materials and fuels as factors of production in industrialised economies, a country that is richly endowed in natural resources benefits from an advantage in terms of lower costs for an input, if only due to economies on transportation costs. This is in addition to the rent received from resource extraction which, under national accounts convention, raises GDP in volume terms even if it reduces national wealth. In practice, historical developments have shown that resource-rich countries are not necessarily better off than countries with meagre endowments, and some of the most remarkable catch-up experiences have been achieved by countries without substantial stocks of resources. Indeed, the literature on the direction of the effect of natural resource endowments on economic performance remains to date largely inconclusive, mainly because natural resources may affect economic growth both directly and indirectly through positive and negative channels. And, the ability of a country to 
benefit most from the positive channels largely depends on other factors, such as political institutions and policy choices.

62. Perhaps the main negative effect of natural resources on growth is the well-known Dutch disease, whereby abundance in a commodity whose relative price on world markets has gone up crowds out activities such as the production of manufactured goods. More specifically, the crowding-out effect is related to positive wealth shocks from the resource sector that boost demand for non-traded goods and drive up non-traded costs and wages. This affects competitiveness adversely in traded-goods sectors - such as manufacturing that use non-traded inputs but obtain revenues from relatively fixed-priced traded goods and leads to a decline in such industries. While the contraction of the tradeable goods sector may be seen as an efficient response to a relative price change in the short run, the risk is that such a re-allocation of resources may be difficult to unwind following an adverse shift in the relative price of natural resources, due to trade hysteresis effects.

63. The long-term negative impact on growth may in such a case be exacerbated if positive externalities in production - such as those arising from learning-by-doing or innovation - are more prevalent in manufacturing than in resources or services industries. The crowding-out hypothesis has received some empirical support, including from studies which found that resource-rich economies generally have higher price levels (even after controlling for income levels) and smaller contribution of manufactured exports to growth (Sachs and Warner, 2001). In a similar vein, it has also been argued by some that the resource rent reduces private incentives to invest in education and R\&D (Papyrakis and Gerlagh, 2004; Douangneune et al., 2005; Gylfason et al., 1999). For example, if wages in the resource sector are relatively high for low-educated persons, individuals may not have sufficient financial incentives to acquire education.

64. Aside from Dutch disease-related factors, a number of less formal channels, mostly based on political economy arguments, have been put forward to account for the perceived negative effect of natural resource abundance on long-term growth (Gylfason, 2007). One is that resource-rich countries are exposed to rent-seeking behaviour on the part of producers or the political elite that controls production and who can use the rent to re-enforce their power, leading to an inefficient use of the resource rent through corruption and misallocation of resources. Such behaviour mostly takes place in a context of weak political institutions and legal infrastructures, more likely to prevail among developing countries. However, even in more advanced countries the resource rent may have adverse long-run effects on growth by reducing incentives to undertake growth-enhancing reforms that are unpopular, or by raising protectionist pressures in response to the decline of manufacturing. Furthermore, insofar as advanced economies choose to manage the resource rent through the creation of a special investment fund (such as in Norway), one challenge is to ensure that management of the fund is sufficiently independent so as to be able to resist political pressures to undertake various types of investment that would clearly fail the market test (e.g. channelling resources to declining industries). Otherwise, the temptation to treat the resource fund as an extension of the State budget may be too strong.

\subsection{Differences in resource endowments across $O E C D$ countries}

65. Various measures of natural resource endowments have been used in the empirical literature. The most direct is wealth in non-renewable natural resources as a share of total wealth as measured by the World Bank (Figure 9, Panel A). A main drawback of such a measure, at least for the purpose of this study, is the lack of a time-series dimension. The main alternatives proposed are usually based on exports of primary products, which may better reflect the economic dependence on natural resources (as opposed to abundance). The most commonly-used indicator is the ratio of gross primary exports to GDP (Sachs and Warner, 1995) (Figure 9, Panel B) but variants have also been proposed, including the share of primary exports in total exports, primary exports over total labour force (Lederman and Maloney, 2003) and the share of mineral exports in merchandise exports (Davis, 1995). The main advantage of these measures is 
the coverage, with time series data on trade in primary products being available for a large set of countries from the World Development Institute, allowing for export-based measures to be used in panel regression analysis.

Figure 9. Measures of natural resource endowments excluding agriculture

A. Stock of natural resources as a percentage of total capital, 2000

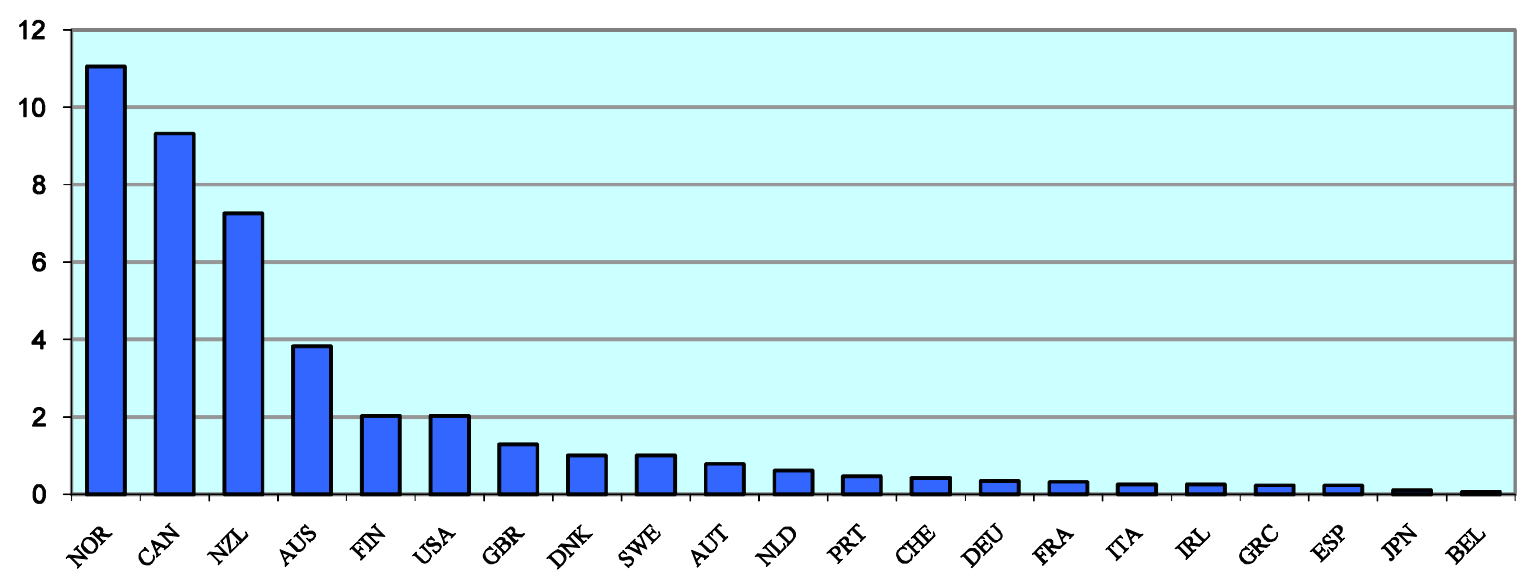

B. Gross exports of primary products as a percentage of GDP, average 2000-2004
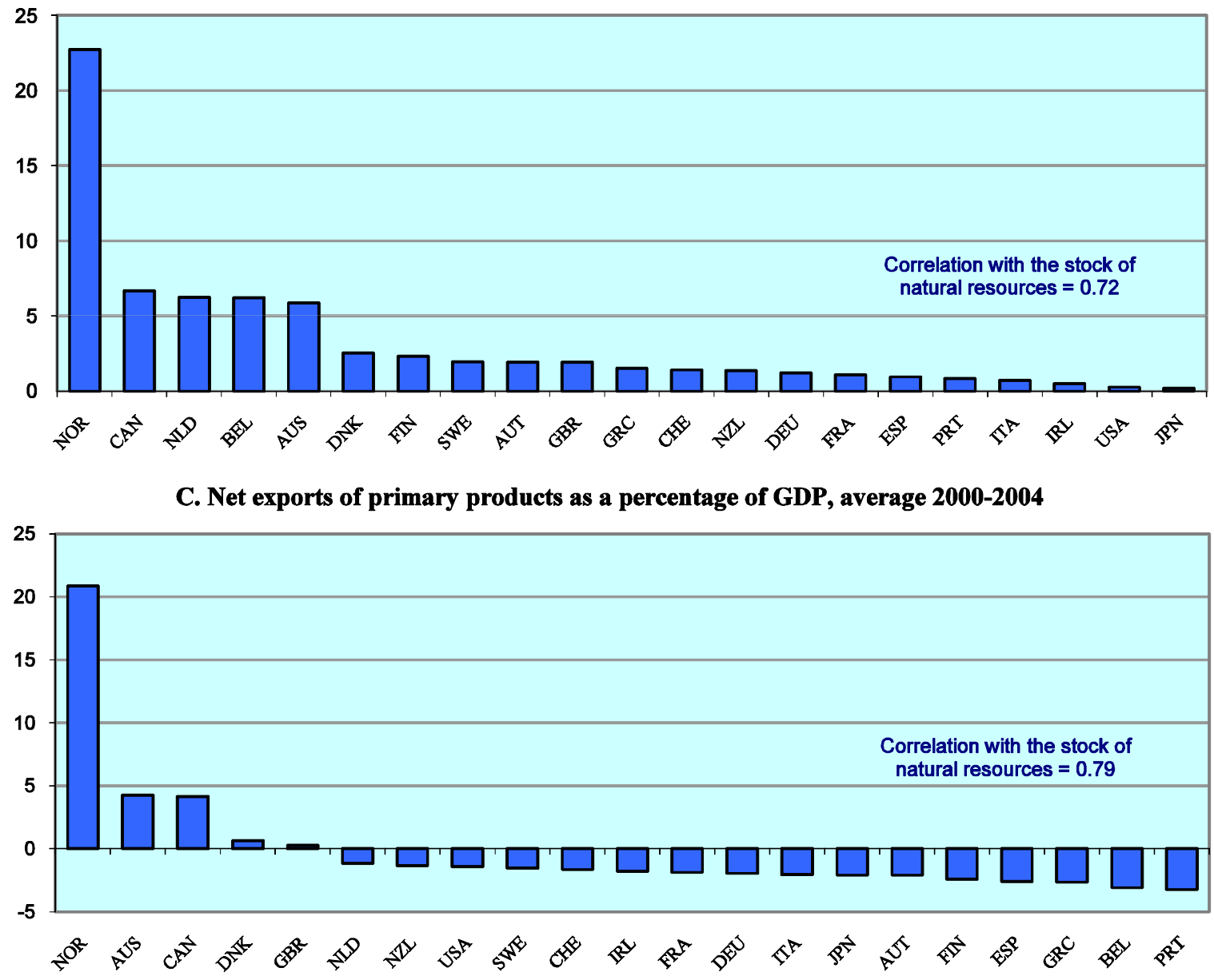

Source: World Bank (panel A), World Development Institute (Panels B and C) and OECD calculations. 
66. However, export-based measures also suffer from two major limitations: one is a misrepresentation of the stock of natural resources for some countries and the other is endogeneity. ${ }^{28}$ For instance, gross primary exports as a share of GDP tends to boost artificially the importance of resource endowments in relatively small countries with high shares of both imports and exports, such as Belgium or Finland (Figure 9, Panel B vs. Panel A). A measure based on the ratio of exports of primary products to total exports is less exposed to this type of distortion. Conversely, the ratio of export to GDP tends to underestimate the underlying share of natural resources in countries that are relatively richly-endowed but also whose domestic consumption tends to be resource-intensive (e.g. the United States). ${ }^{29}$ All exportbased measures share the problem of reverse causality: Lower-income countries tend to have higher exports of primary products relative to GDP — or even more so relative to total exports - regardless of their true endowments.

67. For these reasons, the variable used in the empirical analysis is measured as the ratio of net exports of primary products (excluding agricultural products) to GDP (Figure 9, Panel C). Relative to the ratio of gross exports to GDP, it is a better proxy for the stock of natural resources ${ }^{30}$ while being less vulnerable to endogeneity than a measure based on gross exports of primary products as a share of total exports. According to this measure, relatively richly-endowed countries include Norway, Australia, Canada, Denmark and the United Kingdom, which are all net exporters of non-agricultural primary products. At the other end, countries least endowed in resources are Spain, Greece, Belgium and Portugal. ${ }^{31}$ The largest differences relative to the measure based on the share of natural resource wealth in total capital (stock measure) are found in the case of Finland and, to a lesser extent, Portugal, since both come out looking less richly endowed on the basis of net exports than suggested on the basis of the stock measure.

\subsection{Impact on GDP: empirical estimates}

68. The measure based on net export as a share of GDP has been added as a potential determinant in the augmented Solow model. The results are reported in Table 7. In the first four columns, the estimated equation is specified in level terms, with controls for first-order autocorrelation, while the last column reports the result for the error-correction specification based on the PMG estimator. In all cases, the longrun impact of resource endowment on the level of GDP per capita is positive and significant. In the level specification, the coefficient varies between 0.21 and just under 0.42 , depending on whether country or year fixed-effects are introduced. The long-run coefficient jumps to 1.1 in the equation expressed in errorcorrection form, a value which does not seem plausible.

28. Indicators based on annual primary exports data may also be highly volatile (Brunnschweiler, 2006), although this can be partly tackled by taking averages over longer periods (Lederman and Maloney, 2003).

29. And resource abundance need not necessarily show up in export of primary products, for instance when it is used to process goods (e.g. energy abundance can result in exports of energy-intensive goods rather than export of energy).

30. Indeed the cross-country correlation with the measure based on the stock of natural wealth rises from 0.72 to 0.79 when net exports of primary products are used as opposed to gross exports.

31. It could be argued that some of these countries are richly endowed in another form of natural resource sun and beaches - which drives tourism but which is ignored in traditional measures. 
Table 7. Basic framework with natural resources ${ }^{1}$

\begin{tabular}{|c|c|c|c|c|c|}
\hline $\begin{array}{l}\text { Dependant variable } \\
\text { GDP per capita }\end{array}$ & $\begin{array}{c}\text { level } \\
\text { AR (1) }\end{array}$ & $\begin{array}{c}\text { level } \\
\text { AR (1) }\end{array}$ & $\begin{array}{c}\text { level } \\
\text { AR (1) }\end{array}$ & $\begin{array}{c}\text { level } \\
\text { AR (1) }\end{array}$ & $\begin{array}{c}\text { Error } \\
\text { correction } \\
\text { PMG }\end{array}$ \\
\hline & (1) & (2) & (3) & (4) & (5) \\
\hline \multicolumn{6}{|l|}{ Common parameters } \\
\hline \multirow[t]{2}{*}{ Physical capital } & $0.190 * * *$ & $0.178 * * *$ & $0.191 * * *$ & $0.194 * * *$ & $0.293 * * *$ \\
\hline & $(0.020)$ & $(0.020)$ & $(0.020)$ & $(0.017)$ & $(0.040)$ \\
\hline \multirow[t]{2}{*}{ Human capital } & $0.314 * *$ & $0.729 * * *$ & $0.327 * * *$ & -0.095 & $0.992 * * *$ \\
\hline & $(0.128)$ & $(0.071)$ & (0127) & $(0.150)$ & $(0.242)$ \\
\hline \multirow[t]{2}{*}{ Population growth ${ }^{2}$} & -0.005 & -0.007 & -0.005 & -0.002 & $-0.354 * * *$ \\
\hline & $(0.018)$ & $(0.022)$ & $(0.018)$ & $(0.018)$ & $(0.076)$ \\
\hline \multirow[t]{2}{*}{ Natural resources } & $0.405 * * *$ & $0.418 * * *$ & $0.401 * * *$ & $0.213^{* *}$ & $1.146 * * *$ \\
\hline & (0.113) & $(0.108)$ & $(0.113)$ & $(0.103)$ & $(0.317)$ \\
\hline Weighted sum of market & $0.050 * * *$ & $0.068 * * *$ & $0.050 * * *$ & $0.060 * * *$ & $0.134 * *$ \\
\hline and supplier access & $(0.015)$ & $(0.009)$ & $(0.015)$ & $(0.016)$ & $(0.054)$ \\
\hline $\mathrm{Rho}^{3}$ & 0.880 & 0.946 & 0.881 & 0.774 & \\
\hline \multicolumn{6}{|c|}{ Country-specific parameters } \\
\hline \multirow[t]{2}{*}{ Lambda $^{4}$} & & & & & $-0.153 * * *$ \\
\hline & & & & & $(0.020)$ \\
\hline Time trend & no & no & yes & yes & yes \\
\hline \multicolumn{6}{|l|}{ Fixed effects } \\
\hline Country & yes & no & no & yes & yes \\
\hline Year & yes & yes & yes & yes & no \\
\hline \multicolumn{6}{|l|}{ Sample size } \\
\hline Total number of observations & 696 & 696 & 696 & 696 & 696 \\
\hline Number of countries & 21 & 21 & 21 & 21 & 21 \\
\hline
\end{tabular}

Note: Standard errors are in brackets. *: significant at $10 \%$ level; ${ }^{* *}$ at $5 \%$ level; ${ }^{* * *}$ at $1 \%$ level.

1. The functional forms corresponding to the "level" and "error-correction" specifications are reported in section 2.2. In the level specification, standard errors are robust to heteroscedasticity and to contemporaneous correlation across panels. In the error-correction specification, only long term parameters are reported.

2. The population growth variable is augmented by a constant factor $(g+d)$ designed to capture trend growth in technology and capital depreciation. This constant factor is set at 0.05 for all countries.

3. rho is the first-order auto-correlation parameter.

4. The parameter lambda is the average of the country-specific speed adjustment parameter, $\lambda_{\mathrm{i}}$.

69. Taken at face value, these results suggest that OECD countries have on average escaped the resource curse and/or the Dutch disease. In this regard, the positive effect of natural resources contrasts with empirical findings based on samples of developed and developing countries (Sachs and Warner, 1995). This could be taken as an indication that the quality of institutions or policies is the real underlying factor driving the negative correlation between resource abundance and income in studies with large crosscountry samples. ${ }^{32}$ The estimates obtained from the two specifications (levels and error-correction) indicate

32. Indeed, recent empirical evidence has shown that the detrimental effects of natural resource abundance on growth is not significant after controlling for institutional quality or trade openness (Brunsschweiler, 2006; Arezki and van der Ploeg, 2007). 
that natural resources contribute to raise GDP per capita relative to the OECD average in Norway and, to a lesser extent, Australia and Canada (Figure 10). The difference in parameter estimates between the level and error-correction specification implies variation over a wide range in the case of Norway (between 8 and 24\%). Most other countries are relatively resource-poor compared with the OECD average and natural resources therefore contribute to lower GDP per capita relative to the average but the effect is less than 5\%.

Figure 10. Estimated impact of natural resources on GDP per capita ${ }^{1}$

Deviation from average OECD country in 2000-04

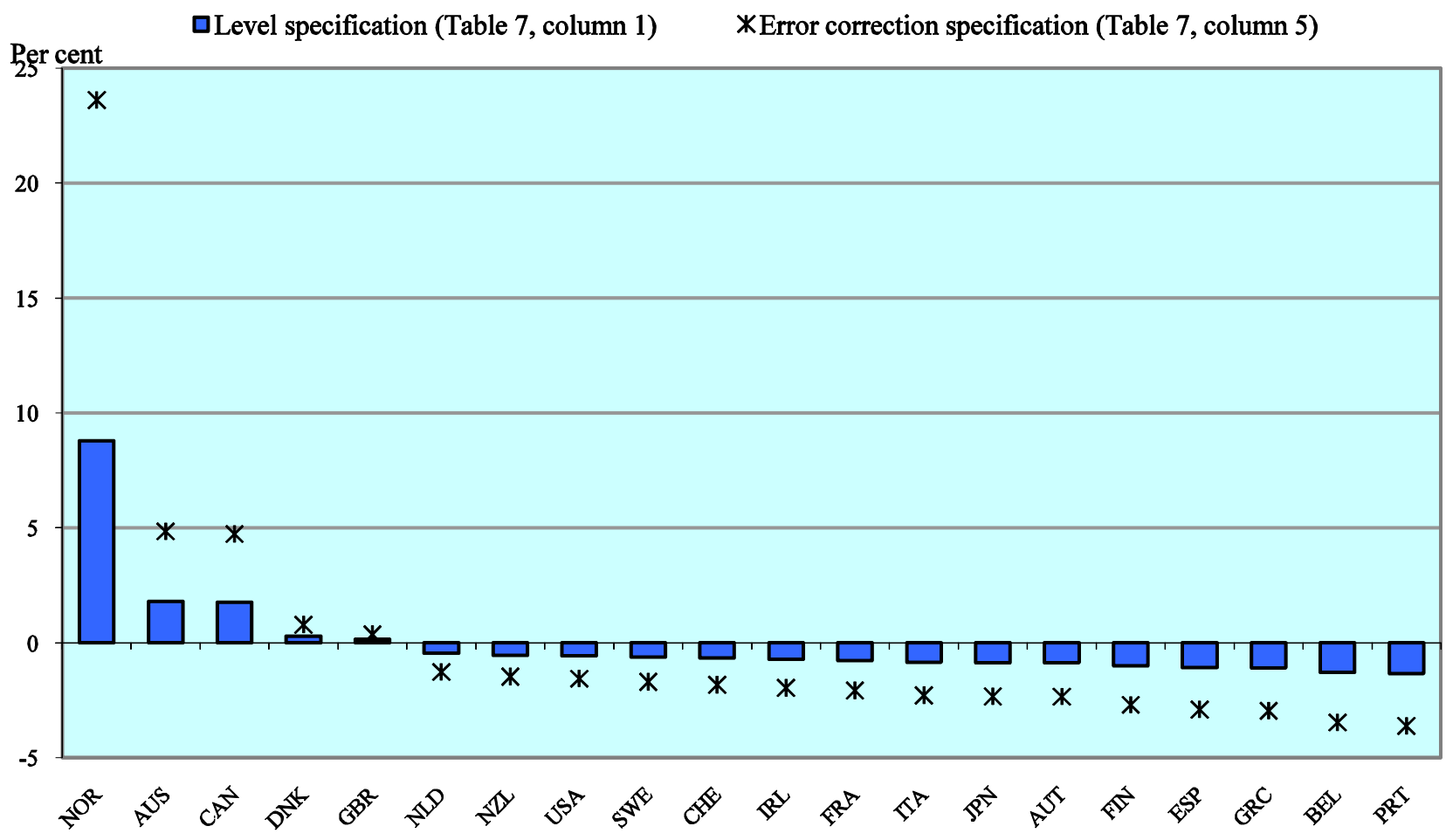

1. Contributions of natural resources to GDP per capita are based on Table 2. They are computed as differences to the average country and on average over the period 2000-04. For example, based on the estimate from the level specification, the favourable resource endowment in Norway contributes to raise his GDP per capita by over $8 \%$. Because of a break in the series due to the reunification, data for Germany were used only for the period 19701989. Therefore, Germany is not included in the figure.

\section{Overall economic impact and policy implications}

\subsection{Overall impact}

70. In order to summarise the contribution of proximity to markets and natural resources to GDP per capita over the whole period, Table 8 uses the parameters estimated from the preferred specification, i.e. column (1) of Table 7. In each case, the contribution is measured relative to the average country, and is reported both as an average over the period 2000-2004 and as a change since 1970. 
Table 8. Impact of market and supplier access and natural resources on GDP per capita, per cent ${ }^{1}$

\begin{tabular}{lcc|cc}
\hline & \multicolumn{2}{c|}{ Market and supplier access } & \multicolumn{2}{c}{ Natural resources } \\
\cline { 2 - 5 } & $\begin{array}{l}\text { Difference to average } \\
\text { country in 2000-2004 }\end{array}$ & $\begin{array}{c}\text { Change } \\
\text { since 1970 }\end{array}$ & $\begin{array}{c}\text { Difference to average } \\
\text { country in 2000-2004 }\end{array}$ & $\begin{array}{c}\text { Change } \\
\text { since 1970 }\end{array}$ \\
\hline Parameter & $(0.050)$ & $(0.050)$ & $(0.405)$ & $(0.405)$ \\
Australia & -10.6 & -1.5 & 1.7 & 0.2 \\
Austria & 1.8 & -0.4 & -0.8 & -0.5 \\
Belgium & 6.7 & 0.2 & -1.2 & -0.3 \\
Canada & 2.1 & 1.1 & 1.7 & -0.4 \\
Denmark & 2.2 & 0.5 & 0.3 & 0.8 \\
Finland & -2.4 & -0.6 & -1.0 & -0.4 \\
France & 3.4 & 0.2 & -0.7 & -0.6 \\
Greece & -3.7 & 0.1 & -1.1 & -1.4 \\
Ireland & 0.6 & -0.6 & -0.7 & -0.5 \\
Italy & 1.3 & 0.0 & -0.8 & -0.4 \\
Japan & 3.0 & 1.0 & -0.8 & 0.0 \\
Netherlands & 5.6 & 0.9 & -0.5 & -0.5 \\
New Zealand & -10.1 & -0.9 & -0.5 & -0.2 \\
Norway & -1.5 & -0.2 & 8.5 & 7.7 \\
Portugal & -2.7 & 1.2 & -1.3 & -1.1 \\
Spain & -1.2 & 1.3 & -1.0 & -0.8 \\
Sweden & -1.4 & -0.7 & -0.6 & -0.6 \\
Switzerland & 3.3 & -1.1 & -0.7 & -0.4 \\
United Kingdom & 3.8 & -1.0 & 0.1 & 0.6 \\
United States & -0.3 & 0.4 & -0.6 & -1.1 \\
Minimum & -10.6 & -1.5 & -1.3 & -1.4 \\
Maximum & 6.7 & 1.3 & 8.5 & 0.0 \\
Average & 0.0 & 0.0 & 0.0 & \\
\hline & & & & \\
\hline
\end{tabular}

1. In order to evaluate the impact of access to markets and natural resources on GDP per capita, the parameters used are those obtained from Table 7, column (1). Based on these estimates, and taking Australia and proximity to markets as an example, the table should be read as follows: compared with the average country in the sample, the distance to markets of Australia contributes to lowering its GDP per capita by $10.6 \%$ on average over the $2000-04$ period. This is an addition of 1.5 points relative to the same contribution calculated for 1970 . Because of a break in the series due to the reunification, data for Germany were used only for the period 1970-1989. Therefore, Germany is not included in the table.

71. Three main results emerge from these calculations. First, as mentioned earlier, the order of magnitude of the impact of remoteness is important, ranging from around -10\% of GDP for Australia and New Zealand to $+6 \%$ for Belgium and the Netherlands. Second, these effects have not changed much over the period, reflecting that geographic factors are generally stable over time. Nevertheless, it seems that the unfavourable position of Oceanic countries has deteriorated somewhat over time, while economic integration has moved Spain, Portugal and Canada closer to central markets. Finally, the contribution of net exports of raw materials is the most significant for Norway, reaching $8.5 \%$ of GDP at the end of the period, while that contribution was minimal in the early 1970s as oil extraction had hardly started at the 
time. Australia and Canada are the two other countries that benefit from natural resources relative to the average country.

72. An alternative way to assess the explanatory power of the geography variables is to compare the standard deviation of the fixed effects before and after the inclusion of these variables. In the augmented Solow model, these country fixed effects account for $72 \%$ of the cross-country variance in GDP per capita (Table 9). ${ }^{33}$ When geography variables are included (Table 7 , column 1 ), the variance explained by the fixed effects is reduced from $72 \%$ to $55 \%$.

Table 9. Size of country fixed effects and share of variance explained by fixed effects

\begin{tabular}{|c|c|c|c|}
\hline & $\begin{array}{l}\text { Average GDP per capita, } \\
\text { 1970-2004 (deviation from } \\
\text { the OECD average) }\end{array}$ & $\begin{array}{c}\text { Fixed effects } \\
\text { Augmented-Solow } \\
\text { Table 1, Column } 1\end{array}$ & $\begin{array}{c}\text { Fixed effects } \\
\text { Augmented-Solow }+ \text { Geography } \\
\text { Table } 7, \text { Column } 1\end{array}$ \\
\hline Australia & 7.9 & 1.9 & 10.6 \\
\hline Austria & 8.5 & 5.2 & 4.1 \\
\hline Belgium & 4.0 & 7.3 & 2.2 \\
\hline Canada & 12.2 & 7.2 & 4.5 \\
\hline Denmark & 11.3 & 10.8 & 9.3 \\
\hline Finland & -3.5 & -4.1 & -0.9 \\
\hline France & 7.6 & 9.5 & 6.8 \\
\hline Greece & -30.8 & -26.0 & -22.2 \\
\hline Ireland & -20.6 & -13.0 & -12.9 \\
\hline Italy & 0.2 & 6.9 & 6.2 \\
\hline Japan & -4.2 & -13.2 & -14.9 \\
\hline Netherlands & 6.5 & 7.0 & 1.6 \\
\hline New Zealand & -21.1 & -24.6 & -14.3 \\
\hline Norway & 27.9 & 22.7 & 19.1 \\
\hline Portugal & -44.6 & -36.3 & -32.8 \\
\hline Spain & -21.1 & -10.1 & -8.2 \\
\hline Sweden & 13.7 & 15.4 & 17.1 \\
\hline Switzerland & 29.1 & 21.9 & 18.9 \\
\hline United Kingdom & -0.4 & 3.0 & -0.8 \\
\hline United States & 17.5 & 14.6 & 15.9 \\
\hline Standard deviation & 0.191 & 0.161 & 0.142 \\
\hline Variance & 0.036 & 0.026 & 0.020 \\
\hline Share of variance & & 0.716 & 0.553 \\
\hline
\end{tabular}

1. Because of a break in the series due to the reunification, data for Germany were used only for the period 19701989. Therefore, Germany is not included in the table.

73. The country fixed effects may in this regard be interpreted as the estimated difference in productivity levels relative to the average country and on average over the whole period of estimation. Based on the standard augmented-Solow model (i.e. ignoring geography), the estimated country fixed effects put Australia slightly above the average country, while New Zealand lags by $25 \%$. Once geography

33. The dispersion across countries of the average (log of) real GDP per capita over the period is 0.191 , whereas the standard deviation of the country fixed effects in the estimated steady-state (Table 1, column 1) is 0.161 and $(0.161 / 0.191)^{2}=72 \%$. 
is controlled for, Australia moves $10 \%$ ahead, suggesting that it has managed to overcome the effect of its unfavorable location, whereas New Zealand remains behind the average country, but only by $14 \%$. Taking geography determinants into account does not change the relative position of the United States, which lies $15 \%$ ahead of the average country. Also, the estimated favorable fixed effects for Belgium and Netherlands in the augmented-Solow framework appear to be almost entirely due to centrality, whereas the converse seems to apply for Finland. ${ }^{34}$

\subsection{Policy implications}

74. The economic-geography effects discussed above imply that GDP-per-capita or productivity gaps cannot on their own be used as a measure of unfinished business of policy. Adopting best practice policy across all policy areas will not allow some countries to attain best performance because they are penalised by their location; others may be able to attain very high levels of performance without aligning their policies on best practice. This section briefly reviews some of the policy issues linked to unfavourable geographical location: how best to minimise the costs due to distance and whether the effectiveness of some structural policies are affected by remoteness.

\subsubsection{Minimising the cost of distance}

75. The high cost of distance, up to $10 \%$ of GDP, raises the question of whether public subsidies to transportation are warranted to reduce shipping costs for companies and individuals. Indeed, if distance has negative externalities, there would seem to be a prima facie case for public intervention to correct such externalities. Budgetary subsidies for urban passenger transportation are common in many OECD countries, but are rare for long-distance, notably cross-border, transportation of goods. However, longdistance transportation already benefits from large implicit subsidies. Most importantly, many transportation activities result in environmental damage, and transportation companies and their clients are not charged for this degradation. This is notably the case for air pollution and greenhouse gas emissions in some modes of transportation where regulations on emissions are lax and fuel use is lightly taxed, air and maritime transportation being prime examples. In most countries, road transportation also benefits from not having to pay for the congestion it causes and free access to the road network. Any decisions to provide additional subsidies to transportation would also have to take into account the cost of raising funds for this purpose, and the risk of failure in managing such subsidies.

76. The authorities can also ensure that prices of transportation services are not inflated by regulations that reduce efficiency and increase costs. Traditionally, transportation sectors have been heavily regulated and exempted from standard competition legislation with adverse effects on costs. Over the past decades, regulations in domestic markets have been eased substantially, especially in road and air transportation (Conway and Nicoletti, 2006). However, cross-border freight transportation is still subject to extensive regulations. Competition pressures in international air routes often remain fairly weak due to restrictive bilateral air service agreements and limits to ownership of national carriers. Road transportation on many international routes is hampered by lack of "cabotage" rights. And international scheduled maritime freight services are still operated as price-setting cartels on many key routes, reflecting that this activity is exempted from national competition legislation in many OECD countries. Moreover, port

34. A similar exercise cannot be replicated concerning the impact of the transport costs variables. The reason is that, as shown in the previous section, the effects of transport costs are robust only via their impact on international trade. The fixed effects obtained from a specification that includes trade openness as a determinant of GDP per capita could have been reported, but these would be misleading as transport costs are one of the determinants of trade only. 
efficiency varies widely across countries and affects shipping costs significantly, in part due to regulatory restrictions hampering competition in port services (Clark, Dollar and Micco, 2004).

\subsubsection{Distance and the effectiveness of structural policies}

77. Remoteness can in principle influence the effectiveness of some structural policy measures, with implications for policy choices A possible interaction between policy and distance is that a given policy change to strengthen competition in domestic product markets may have a weaker influence in remote countries than in countries close to large markets, even if such reforms are arguably more needed in the former group of countries as they have limited alternatives to enhance competition. In countries at a large distance from world markets, there may not be room for many competitors in some sectors if the efficient scale of operation is close to the size of the market. In such circumstances the lifting of statutory entry barriers may not stimulate entry, as the size of the market will de facto restrict the number of competitors. On the other hand, if legal entry barriers are the binding constraint on entry as seems more likely in countries close to world markets, then lowering such barriers should stimulate competition. Notwithstanding the intuitive appeal of such arguments, no evidence that distance significantly interacts with a measure of competition-restraining regulations could be found on the basis of an admittedly crude empirical investigation. Indeed, the first three columns of Table 10 show, first, that both product market regulation and access to markets remain significant when they are jointly included in the basic equation and, second, that the interaction between regulation and proximity is not significant. 
Table 10. Geography and the effectiveness of structural policies ${ }^{1}$

\begin{tabular}{|c|c|c|c|c|c|c|c|c|}
\hline $\begin{array}{l}\text { Dependant variable } \\
\text { GDP per capita }\end{array}$ & $\begin{array}{c}\text { level } \\
\text { AR (1) }\end{array}$ & $\begin{array}{c}\text { level } \\
\text { AR (1) }\end{array}$ & $\begin{array}{c}\text { level } \\
\text { AR (1) }\end{array}$ & $\begin{array}{c}\text { level } \\
\operatorname{AR}(1)\end{array}$ & $\begin{array}{c}\text { level } \\
\text { AR (1) }\end{array}$ & $\begin{array}{c}\text { level } \\
\operatorname{AR}(1)\end{array}$ & $\begin{array}{c}\text { level } \\
\text { AR (1) }\end{array}$ & $\begin{array}{c}\text { level } \\
\operatorname{AR}(1)\end{array}$ \\
\hline & (1) & (2) & (3) & (4) & (5) & (6) & (7) & (8) \\
\hline \multirow[t]{2}{*}{ Physical capital } & $0.209^{* * *}$ & $0.214^{* * *}$ & $0.213^{* * *}$ & $0.222^{* * *}$ & $0.213^{* * *}$ & $0.233^{* * *}$ & $0.230^{* * *}$ & $0.231^{* * *}$ \\
\hline & $(0.021)$ & $(0.022)$ & $(0.022)$ & $(0.023)$ & $(0.023)$ & $(0.024)$ & $(0.024)$ & $(0.023)$ \\
\hline \multirow[t]{2}{*}{ Human capital } & $0.240^{* * *}$ & $0.240 * * *$ & $0.207^{* * *}$ & $0.203^{* *}$ & $0.223^{* *}$ & $0.371^{* * *}$ & $0.472^{* * *}$ & $0.574^{* * *}$ \\
\hline & $(0.087)$ & $(0.079)$ & $(0.080)$ & $(0.090)$ & $(0.095)$ & $(0.119)$ & $(0.127)$ & $(0.140)$ \\
\hline \multirow{2}{*}{ Population growth $^{2}$} & -0.031 & -0.021 & -0.022 & 0.018 & 0.019 & -0.005 & -0.010 & -0.009 \\
\hline & $(0.021)$ & $(0.022)$ & $(0.022)$ & (0.035) & $(0.035)$ & $(0.022)$ & $(0.022)$ & $(0.022)$ \\
\hline Weighted sum market & & $0.053 * * *$ & $0.050 * * *$ & & $0.041^{* *}$ & $0.036^{*}$ & $0.043 * *$ & $0.039 * *$ \\
\hline and supplier access & & $(0.018)$ & $(0.018)$ & & $(0.021)$ & (0.019) & $(0.020)$ & $(0.019)$ \\
\hline \multirow[t]{2}{*}{ Natural resources } & & $0.421^{* * *}$ & $0.407^{* * *}$ & & & $0.362^{* *}$ & $0.347 * *$ & $0.298^{* *}$ \\
\hline & & $(0.127)$ & $(0.126)$ & & & $(0.141)$ & $(0.141)$ & $(0.138)$ \\
\hline \multirow[t]{2}{*}{$\mathrm{PMR}^{3}$} & $-0.035^{*}$ & $-0.044^{* *}$ & $-0.041^{* *}$ & & & & & \\
\hline & $(0.019)$ & $(0.020)$ & $(0.020)$ & & & & & \\
\hline \multirow[t]{2}{*}{ PMR*Population density } & & 0.006 & & & & & & \\
\hline & & $(0.006)$ & & & & & & \\
\hline PMR*Weighted sum market & & & -0.004 & & & & & \\
\hline and supplier access & & & $(0.009)$ & & & & & \\
\hline \multirow[t]{2}{*}{ Business R\&D ${ }^{4}$} & & & & $0.027^{*}$ & $0.031^{*}$ & & & \\
\hline & & & & $(0.015)$ & $(0.016)$ & & & \\
\hline Business R\&D*Urban & & & & & $0.114^{* *}$ & & & \\
\hline concentration & & & & & $(0.056)$ & & & \\
\hline Business R\&D*Weighted sum & & & & & 0.007 & & & \\
\hline market and supplier access & & & & & $(0.009)$ & & & \\
\hline Human capital*Urban & & & & & & $0.886^{* * *}$ & & $1.271^{* * *}$ \\
\hline concentration ${ }^{3}$ & & & & & & $(0.191)$ & & $(0.260)$ \\
\hline Human capital*Population & & & & & & & $-0.117^{* * *}$ & $-0.204 * * *$ \\
\hline density $^{6}$ & & & & & & & $(0.036)$ & $(0.048)$ \\
\hline \multirow[t]{2}{*}{ Time trend } & $0.017^{* * *}$ & $0.017^{* * *}$ & $0.017^{* * *}$ & $0.020^{* * *}$ & $0.020^{* * *}$ & $0.018^{* * *}$ & $0.017^{* * *}$ & $0.016^{* * *}$ \\
\hline & $(0.001)$ & $(0.001)$ & $(0.001)$ & $(0.001)$ & $(0.001)$ & $(0.001)$ & $(0.001)$ & $(0.001)$ \\
\hline Rho' $^{\prime}$ & 0.843 & 0.817 & 0.828 & 0.857 & 0.853 & 0.829 & 0.842 & 0.855 \\
\hline \multicolumn{9}{|l|}{ Füxed effects } \\
\hline Country & yes & yes & yes & yes & yes & yes & yes & yes \\
\hline \multicolumn{9}{|l|}{ Sample size } \\
\hline Total number of observations & 595 & 595 & 595 & 344 & 344 & 696 & 696 & 696 \\
\hline Number of countries & 21 & 21 & 21 & 21 & 21 & 21 & 21 & 21 \\
\hline
\end{tabular}

Note: Standard errors are in brackets. *: significant at $10 \%$ level; ** at $5 \%$ level; ${ }^{* *}$ at $1 \%$ level.

1. The functional form corresponding to the "level" specification is reported in section 2.2. Standard errors are robust to heteroscedasticity and to contemporaneous correlation across panels. All interaction variables are constructed from the demeaned respective variables. That way, the estimated parameters on the non-interacted variables still measure the average effect of these variables.

2. The population growth variable is augmented by a constant factor $(g+d)$ designed to capture trend growth in technology and capital depreciation. This constant factor is set at 0.05 for all countries.

3. PMR is the product market regulation index which is built in a 0-6 scale. It is introduced in logs.

4. Due to limitations in data, the sample for regressions involving $R \& D$ spending is substantially reduced. This is because data on R\&D are generally only available from 1981 to $2003 / 04$, and 6 of the 21 countries do not have sufficiently long series to be included. Note also that private R\&D is entered in the regression with one lag.

5. Urban concentration is the share of the country population living in cities of more than 1 million inhabitants.

6. Population density measure is the ratio of population to surface area.

7. rho is the first-order auto-correlation parameter. 
78. Another area where the effectiveness of policies might be expected to vary depending on distance is $R \& D$ spending. ${ }^{35}$ Such activity is likely to involve significant fixed costs and thus be subject to economies of scale. With distance limiting the size of the market, the unit cost of innovation can be expected to be higher in remote countries than in countries close to large markets where fixed costs can be spread more widely. Hence, a given increase in public and/or private R\&D spending is likely to have a greater leverage and therefore a greater GDP-per-capita impact in countries with short distance to markets than in more remote countries. Furthermore, insofar as the effectiveness of public and/or private R\&D can be influenced by the strength of industry and science linkages or by close interactions between researchers from various institutions, the impact of R\&D on GDP per capita may vary according to the extent of urban concentration within a country.

79. These possibilities are examined via the introduction in the estimated equation of two interaction terms, one between private $R \& D$ and distance and the other between private $R \& D$ and the share of the country population living in cities of more than 1 million inhabitants (urban concentration). A measure of R\&D intensity (business R\&D as a ratio of GDP) is first introduced as an additional determinant in the augmented Solow model (Column 4), where it comes out significant (although at the 10 per cent confidence level). The specification with the two interaction terms is then shown in Column 5 of Table 10, where the results suggest that the effectiveness of private $R \& D$ intensity is significantly influenced by the degree of urban concentration, but not by distance to major markets. ${ }^{36}$

80. A third policy area where geographic factors might be important is human capital formation. In this case, however, the relevant geographic factor is not distance to world markets but rather economic density, in particular the degree of agglomeration. A hypothetical benefit of agglomeration is that there are strong knowledge spillovers associated with proximity, whereby "tacit" or informal knowledge is transmitted via face-to-face contact. To the extent that such kind of knowledge is related to cognitive skills acquired during formal schooling, reforms that strengthen educational performance may have stronger productivity raising effects in densely populated urban centres than in areas where population density is lower. If this were to be the case, countries where the population is concentrated in large urban areas would benefit more from educational reforms than countries where the population settlement is more dispersed. The preliminary empirical evidence, as reported in the last three columns of Table 10, is inconclusive. Taking the estimates at face value, the impact of human capital on GDP per capita seems to be strengthened by urban concentration, whereas the opposite result is obtained when the density measure is the ratio of population to surface area.

\section{Conclusions}

81. This paper examines how much of the dispersion in economic performance across OECD countries can be accounted for by economic geography factors. More specifically, two aspects of economic geography have been examined, namely the proximity to areas of dense economic activity and endowments in natural resources. To do so, various indicators of distance to market, transportation costs, and dependence on natural resources have been added sequentially as determinants in an augmented Solow model, which is used as a benchmark.

35. R\&D spending was left out from the specifications in previous sections because limitations in data availability would have led to a substantial reduction in sample size (from nearly 600 to around 350 observations), and also because the focus of the study is on economic geography determinants.

36. In this specification, the ratio of R\&D spending to GDP is used as a proxy for investment in innovation. Although in absence of knowledge depreciation, a decline in the R\&D intensity should not lead to a fall in GDP per capita, the specification implies that a switch to a steady-state corresponding to a lower R\&D intensity would entail moving to a path with a lower GDP per capita. 
82. Three measures of distance to markets are found to have a statistically significant effect on GDP per capita: the sum of bilateral distances, market potential and the weighted sum of market access and supplier access. And the estimated economic impact, which varies somewhat across specifications, is far from negligible. For instance, the lower access to markets relative to the OECD average could contribute negatively to GDP per capita by as much as $10 \%$ in Australia and New Zealand. Conversely, the benefit from a favourable location could account for as much as 6-7\% of GDP in the case of Belgium and the Netherlands. The impact of transport costs on GDP per capita is also found to be statistically significant, albeit less so in economic terms. For instance, differences in transport costs relative to the OECD average contribute to reduce GDP per capita by between $1.0 \%$ and $4.5 \%$ in Australia and New Zealand. At the other end, the lower transport costs for Canada and the United States contributes to raise GDP per capita relative to the average OECD country, but only by a small margin varying between $0.5 \%$ and. $2.5 \%$. These quantitatively smaller effects are consistent with transportation costs being only one aspect of distancerelated costs. Finally, endowments in natural resources, as measured by the ratio of net exports of primary products (excluding agriculture) to GDP, are found to have a significant positive effect on GDP per capita. This suggests that OECD countries have, on average, escaped the natural resource curse or severe forms of Dutch disease.

83. Considering the substantial estimated effect that distance/proximity to major markets has on GDP per capita, one issue is whether there is a role for public authorities to subsidise international transport, at least in the most remote countries, so as to partly compensate for additional trade costs incurred. Against this, it can be argued that transport is already subsidised in many ways, if only because transport industries only partly bear the cost of negative externalities such as pollution and road congestion. Moreover, subsidisation involves well-known issues of government failure. Less controversial, public policies can also contribute to reduce the cost of transportation by strengthening competition in transport industries, which have in the past been heavily regulated. However, considering that since the mid-1980s domestic regulation has been eased to some extent, at least in air and road transport, further gains in this area may come from reductions in regulatory barriers to cross-border freight transport, an area where less progress has been achieved.

84. Insofar as distance or remoteness may affect the effectiveness of policy, another policy issue is whether the possibility that what constitutes "best practice" in a particular area may differ across countries. Some tentative estimates of these effects have been conducted with respect to product market regulation, human capital and R\&D spending. The preliminary results do not provide strong evidence of an impact of remoteness on the effectiveness of policy in these areas. However, there is some evidence that spending on R\&D and human capital might have a stronger effect on GDP per capita in countries with higher urban concentration. 
ECO/WKP(2008)10

\section{REFERENCES}

Arezki, R. and F. Van der Ploeg (2007), "Can the Resource Curse Be Turned into a Blessing? The Role of Trade and Institutions", IMF Working Paper No. 07/55

Arnold, J., A. Bassanini and S. Scarpetta (2008), "Is it Solow or Lucas ?", OECD Economics Department Working Paper, forthcoming.

Bassanini, A. and S. Scarpetta (2001), "Does Human Capital Matter for Growth in OECD Countries? Evidence from PMG Estimates", OECD Economics Department Working Paper No. 282.

Beck, N. and J.N. Katz (2004), "Time Series Cross Section Issues: Dynamics, 2004”, Paper presented at the 2004 Annual Meeting of the Society for Political Methodology, Stanford University.

Bernanke, B.S. and R.S. Gürkaynak (2001), "Is Growth Exogenous? Taking Mankiw, Romer and Weil Seriously", NBER Macroeconomics Annual.

Blonigen, B. and W. Wilson (2006), "New Measures of Port Efficiency Using International Trade Data", NBER Working Paper No. 12052.

Boulhol, H. and A. de Serres (2008), "Have Developed Countries Escaped the Curse of Distance?", OECD Economics Department Working Papers, forthcoming.

Breinlich, H. (2007), "The Spatial Income Structure in the European Union - What Role for Economic Geography?", Journal of Economic Geography, forthcoming.

Brunnschweiler, C. (2006), "Cursing the Blessings? Natural Resource Abundance, Institutions and Economic Growth", Economics Working Paper Series 06/51, ETH Zurich

Clark, X., D. Dollar and A. Micco (2004), "Port efficiency, Maritime Transport Costs, and Bilateral Trade", Journal of Development Economics, Vol. 75, No. 2.

Combes, P.-P. and H.G. Overman (2004), "The Spatial Distribution of Economic Activities in the European Union", in V. Henderson and J.-F. Thisse (eds.), Handbook of Urban and Regional Economics, Vol. 4, Elsevier-North Holland, Amsterdam.

Conway, P. and G. Nicoletti (2006), "Product Market regulation in the Non-Manufacturing Sectors of OECD Countries: Measurement and Highlights", OECD Economics Department Working Papers, No. 530

Davis, G.A., 1995, "Learning to Love the Dutch Disease: Evidence from the Mineral Economies", World Development, Vol. 23, No. 10.

Dolman, B., D. Parham and S. Zheng (2007), “Can Australia Match US Productivity Performance?", Australia Government Productivity Commission, Staff Working Paper, March. 


\section{ECO/WKP(2008)10}

Durlauf, S.N. and D. Quah (1999), "The New Empirics of Economic Growth", Handbook of Macroeconomics, Vol. 1, Chapter 4, J.B. Taylor and M. Woodford eds.

Douangneune, B., Y. Hayami and Y. Godo, (2005), "Education and Natural Resources in Economic Development: Thailand Compared with Japan and Korea”, Journal of Asian Economics, Vol. 16, No. 2.

Eaton, J. and S. Kortum (1994), "International Patenting and Technology Diffusion", NBER Working Paper No. 4931.

Eaton, J. and S. Kortum (1996), "Trade in Ideas: Patenting and Productivity in the OECD", Journal of International Economics, Vol. 40, No. 3-4.

Frankel, J. and D. Romer (1999), “Does Trade Cause Growth?”, American Economic Review, Vol. 84, No. 1.

Golub, S.S. and B. Tomasik (2008), "Measures of International Transport Cost for OECD Countries", OECD Economics Department Working Papers, forthcoming.

Gylfason, T. (2007), "The International Economics of Natural Resources and Growth", CES IFO Working Paper No. 1994.

Gylfason, T., T.T. Herbertsson and G. Zoega (1999), "A Mixed Blessing: Natural Resources and Economic Growth", Macroeconomic Dynamics, Vol. 3, No. 2.

Hall, R.E. and C.I. Jones (1999), "Why do some countries produce so much more output per worker than others?", Quarterly Journal of Economics, Vol. 114, No. 1.

Hanson, G.H. (2005), "Market Potential, Increasing Returns and Geographic Concentration", Journal of International Economics, Vol. 67, No. 1.

Harris, C. (1954), "The Market as a Factor in the Localization of Industry in the United States", Annals of the Association of National Geographers, Vol. 44, No. 4.

Head, K. and T. Mayer (2006), "Regional Wage and Employment Responses to Market Potential in the EU”, Regional Science and Urban Economics, Vol. 36, No. 5.

Hummels, D. (2007), “Transportation Costs and International Trade in the Second Era of Globalization", Journal of Economic Perspectives, Vol. 21.

Hummels, D. (2006), "Transportation Costs and International Trade in the Second Era of Globalization", Journal of Economic Perspectives, Vol. 21, No. 3.

Hummels, D. (2001), “Time as a Trade Barrier”, Unpublished paper, Purdue University.

Hummels, D. (1995), “Global Income Patterns: Does Geography Play a Role?”, Chapter II of PhD Thesis, University of Michigan.

Islam, N. (1998), "Growth Empirics: a Panel Data Approach - a Reply", Quarterly Journal of Economics, Vol. 113, No. 1. 
Keller, W. (2002), "Geographic Localization of International Technology Diffusion", American Economic Review Vol. 92, No. 1.

Lederman, D. and W.F. Maloney (2003), “Trade Structure and Growth”, World Bank Policy Research Working Paper No. 3025.

Lee, K., M. H. Pesaran and R. Smith (1997), "Growth and Convergence in a Multi-Country Empirical Stochastic Solow Model”, Journal of Applied Econometrics, Vol. 12, No. 14.

Mankiw, G.N., D.Romer and D.Weil (1992), "A contribution to the empirics of economic growth", Quarterly Journal of Economics, 107, No. 2.

Nicoletti, G., S. Golub, D. Hajkova, D. Mirza and K.-Y. Yoo (2003), "Policies and International Integration: Influences on Trade and Foreign Direct Investment", OECD Economics Studies, No. 36.

Nordås, H. (2006), “Time as a Trade Barrier: Implications for Low-Income Countries", OECD Economic Studies, No. 42.

Nordås, H., E. Pinali and M. G. Grosso (2006), "Logistic and Time as a Trade Barrier", OECD Trade Policy Working Papers, No. 35.

OECD (2003), The Sources of Economic Growth in OECD Countries, Paris.

OECD (2006), OECD Employment Outlook, Paris.

Papyrakis, E. and R. Gerlagh (2004), "The Resource Curse Hypothesis and its Transmission Channels", Journal of Comparative Economics, Vol. 32, No. 1.

Pesaran, M.H., Y. Shin and R. Smith (1999), "Pooled Mean Group Estimation of Dynamic Heterogeneous Panels", Journal of the American Statistical Association, Vol. 94, No. 3.

Piras, R. (1997), “On Lucas’s Model of Endogenous Growth”, Economic Notes, Vol. 26, No. 1.

Redding, S. and P.K. Scott (2003), "Distance, Skill Deepening and Development: Will Peripheral Countries Ever Get Rich?”, Journal of Development Economics, Vol. 72, No. 2.

Redding, S. and A.J. Venables (2004), "Economic Geography and International Inequality", Journal of International Economics, Vol. 62, No. 1.

Sala-i-Martin, X., G. Doppelhofer and R. Miller (2004), "Determinants of Long-Term Growth: A Bayesian Averaging of Classical Estimates Approach", American Economic Review, Vol. 94, No. 4.

Sachs, J.D. and A.M. Warner (1995), "Natural Resource Abundance and Economic Growth", NBER Working Paper No. 5398.

Sachs, J.D. and A.M. Warner (2001), "The Curse of Natural Resources", European Economic Review, Vol. 45, No. 4-6.

Solow, R. (1956), "A Contribution to the Theory of Economic Growth", Quarterly Journal of Economics, Vol. 70, No. 1. 


\section{ANNEX: THE AUGMENTED SOLOW MODEL}

\section{A.1. The augmented Solow model in empirical analysis}

85. The Solow (1956) model has been widely used as a theoretical framework to explain differences across countries in income levels and growth patterns. The model is based on a simple production function with constant returns-to-scale technology. In the augmented version of the model (Mankiw, Romer and Weil, 1992), output is a function of human and physical capital, as well as labour (working-age population) and the level of technology. Under a number of assumptions about the evolution of factors of production over time, the model can be solved for its long-run (steady-state) equilibrium whereby the path of output per capita is determined by the rates of investment in physical and human capital, the level of technology, and the growth rate of population. In the steady-state, the growth of GDP per capita is driven solely by technology, which is assumed to grow at a (constant) rate set exogenously in the basic model.

86. In an earlier analysis, summarised in OECD (2003), a wide range of variables were added to the basic model as potential determinants. For instance, in the specifications based on economy-wide data, the set of additional variables included measures of inflation, indicators of government size and financing, measures of R\&D intensity, as well as proxies for financial development and exposure to international trade. Given the large number of potential determinants, as well as their heterogeneity in terms of country coverage and time-series availability, the additional variables were never introduced all at once but rather by groups through various specifications. However, the three basic determinants of the augmented-Solow model - physical capital, human capital and population growth - were systematically included in all specifications. And, the coefficient estimates on these core variables appeared fairly robust to the sequential inclusion of the additional variables.

87. The long-run relationship derived from the augmented Solow model can be estimated either directly in its level form, or through a specification that explicitly takes into account the dynamic adjustment to the steady state. Estimates of the long-run relationship in static form have been used in the literature (e.g. Mankiw, Romer and Weil, 1992; Hall and Jones, 1999; Bernanke and Gürkaynak, 2001), in particular in studies focusing on income level differentials across countries. However, since the model has often been used in the empirical growth literature to examine issues of convergence, some form of dynamic specification has been more common. The two types of specification - static or dynamic - can be expected to yield similar results if countries are not too far from their steady-states or if deviations from the latter are not too persistent.

88. In principle, a dynamic specification is preferable, even when the interest is mainly on the identification of long-run determinants. This is because persistent deviations from steady-state are more likely to lead to biased estimates of the long-run parameters in static regressions, especially when the timeseries dimension of the sample is relatively short, as is the case for this study (maximum length 1970-2004). In practice, estimating dynamic panel equations is also fraught with econometric problems (Durlauf and Quah, 1999). Furthermore, a major drawback with the most common techniques based on dynamic fixed-effect estimators is that only the intercepts are allowed to vary across countries, implying that all countries converge to their steady-state at the same speed, an assumption unlikely to hold even among developed countries. ${ }^{37}$

37. The implications of imposing invalid homogeneity restrictions on slope parameters in the context of dynamic panel estimates are discussed in Lee, Pesaran and Smith (1997). 
89. To address the latter issue, the previous OECD analysis relied essentially on the Pooled Mean Group (PMG) estimator, which allows for short-run coefficients and the speed of adjustment to vary across countries, while imposing homogeneity on long-run coefficients. However, even though the PMG estimation technique is intuitively appealing and perhaps the most suitable under some conditions, it is not without limitations especially when such conditions are not met. For instance, due to the large number of parameters and the non-linear constraints, the maximum likelihood estimation technique is prone to problems of convergence on local optima. And, experience suggests that parameter estimates can be particularly sensitive in presence of multi-collinearity among regressors, with some parameter values being in such cases too large (and unstable) to be plausible.

\section{A.2. Formal presentation of the model ${ }^{38}$}

90. The underlying growth framework is the neoclassical growth model augmented with human capital (Mankiw, Romer and Weil, 1992). The production function is Cobb-Douglas:

$$
Y(t)=K(t)^{a} H(t)^{b}(A(t) L(t))^{1-a-b}
$$

where $Y, L, K$ and $H$ are output, labour, physical and human capital, respectively, and $A$ is the level of technology. $L$ and $A$ are assumed to grow exogenously at rates $n$ and $g . s_{k}$ and $s_{h}$ being the investment rates in physical and human capital respectively, the dynamics of the reproducible factors are:

$$
\begin{aligned}
& \dot{k}(t)=s_{k}(t) A(t)^{1-a-b} k(t)^{a} h(t)^{b}-(n(t)+d) k(t) \\
& \dot{h}(t)=s_{h}(t) A(t)^{1-a-b} k(t)^{a} h(t)^{b}-(n(t)+d) h(t)
\end{aligned}
$$

where $k \equiv K / L$ and $h \equiv H / L$ denote the stocks of capital per unit of labour and $d$ is the time-invariant depreciation rate. Under the assumption of decreasing returns to physical and human capital $(a+b<1)$, this growth model generates the following steady states, denoted by ${ }^{*}$, where $y \equiv Y / L$ :

$$
\begin{aligned}
\log _{k^{*}}(t) & =\log A(t)+\frac{1-b}{1-a-b} \log s_{k}(t)+\frac{b}{1-a-b} \log s_{h}(t)-\frac{1}{1-a-b} \log (g+d+n(t)) \\
\log h^{*}(t) & =\log A(t)+\frac{a}{1-a-b} \log s_{k}(t)+\frac{1-a}{1-a-b} \log s_{h}(t)-\frac{1}{1-a-b} \log (g+d+n(t)) \\
\log y^{*}(t) & =\log A(t)+\frac{a}{1-a}\left(\log s_{k}(t)-\log (g+d+n(t))\right)+\frac{b}{1-a} \log ^{*}(t)
\end{aligned}
$$

The steady-state of human capital in the last equation is unobservable, but a log-linearisation leads to:

$$
\log ^{*}(t)=\log h(t)+\xi . \Delta \log h(t)
$$

$\xi$ being a function of the technological parameters $(a, b)$. Consequently, the income steady-state is given by the following level equation:

$$
\log y^{*}(t)=\frac{a}{1-a} \log s_{k}(t)-\frac{a}{1-a} \log (g+d+n(t))+\frac{b}{1-a} \log h(t)+\frac{b}{1-a} \xi \log h(t)+\log A(0)+g t
$$

(level equation)

38. This section borrows from Bassanini and Scarpetta (2001). 
91. The level equation ignores the dynamics to the steady state. A linear approximation of the transitional dynamics can be expressed as follows:

$$
\begin{aligned}
& \log y(t)=(1-\lambda) \log y(t-1)+\lambda \log y^{*}(t) \Leftrightarrow \\
& \Delta \log y(t)=-\lambda\left[\log y(t-1)-\left(\frac{a}{1-a} \log s_{k}(t)-\frac{a}{1-a} \log (g+d+n(t))+\frac{b}{1-a} \log h(t)+\frac{b}{1-a} \xi \Delta \log h(t)+g t+\psi\right)\right]
\end{aligned}
$$

where $\lambda \equiv(1-a-b)(g+d+\bar{n})$ is the annual speed of convergence and $\psi=\log A(0)+g(1-\lambda) / \lambda$ is a constant. In order to obtain the error-correction form, short-run dynamics around the transition path has to be accounted for. Taking the maximum lag as being one, the following is obtained:

$$
\begin{aligned}
\Delta \log y(t)= & -\lambda\left[\log y(t-1)-\left(\frac{a}{1-a} \log s_{k}(t)-\frac{a}{1-a} \log (g+d+n(t))+\frac{b}{1-a} \log h(t)+\frac{b}{1-a} \xi \Delta \log h(t)+g t\right)\right] \\
& +a_{0}+a_{1} \Delta \log s_{k}(t)+a_{2} \Delta \log (g+d+n(t))+a_{3} \Delta \log h(t)+a_{4} \Delta^{2} \log h(t)
\end{aligned}
$$

(error correction equation)

92. The error correction equation could be estimated by imposing the homogeneity of all the coefficients across countries. Such restrictions are generally not supported by the data. An alternative specification, the Pooled Mean Group, proposed by Pesaran, Shin and Smith (1999) consists in allowing short-run coefficients, the speed of adjustment and error variances to differ across countries, while imposing homogeneity on long-run coefficients. Formally, the following specification is estimated:

$$
\begin{aligned}
\Delta \log y_{i}(t)= & -\lambda_{i}\left[\log y_{i}(t-1)-\left(\frac{a}{1-a} \log _{s_{k i}}(t)-\frac{a}{1-a} \log \left(g+d+n_{i}(t)\right)+\frac{b}{1-a} \log h_{i}(t)+\frac{b}{1-a} \xi \Delta \log h_{i}(t)+g t\right)\right] \\
& +a_{0 i}+a_{1 i} \Delta \log _{k i}(t)+a_{2 i} \Delta \log \left(g+d+n_{i}(t)\right)+a_{3 i} \Delta \log h_{i}(t)+a_{4 i} \Delta^{2} \log h_{i}(t)+\varepsilon_{i t}
\end{aligned}
$$

$\varepsilon_{i t}$ i.i.d. across $i$ and $t \quad, \quad \operatorname{Var}\left(\varepsilon_{i t}\right)=\sigma_{i}^{2}$

(error correction equation, PMG)

93. It is common to impose $g+d$ in $\log (g+d+n(t))$ to be equal to 0.05. Based on the CobbDouglas production function, the physical and capital shares are equal to $a$ and $b$, respectively. These two parameters should therefore be around 1/3. Consequently, the coefficients that are consistent with the model above should be close to 0.5 for both $\log s_{k}$ and $\log s_{h}$, with a speed of convergence of around $(1-a-b)(g+d+\bar{n}) \approx(1-1 / 3-1 / 3) .(0.05+0.02) \approx 0.023$.

94. The empirical framework above is actually fairly general and consistent with various endogenous growth models, but with different interpretation of the parameters (Bernanke and Gürkaynak, 2001). In particular, the Uzawa-Lucas model generates the following steady state (Piras, 1997; Bassanini and Scarpetta, 2001):

$$
\log y^{*}(t)=\frac{a}{1-a} \log s_{k}(t)-\frac{a}{1-a} \log (\tilde{g}+d+n(t))+\log h(t)+\log A(0)+g t
$$

where $\tilde{g} \equiv g+\gamma_{h^{*}}$ is the steady-state growth rate of GDP per capita, which is the sum of the exogenous growth rate, $g$, and of the equilibrium growth rate of human capital per effective unit of labour, $\gamma_{h^{*}}$. 
Therefore, one can still assume $\tilde{g}+d=0.05$. Thus, the steady-state equation is similar to that obtained in the augmented Solow model, but with the prediction that the coefficient for human capital is equal to 1 . The transitional dynamics along the stable path is:

$$
\Delta \log y(t)=-\tilde{\lambda}\left[\log y(t-1)-\left(\frac{a}{1-a} \log s_{k}(t)-\frac{a}{1-a} \log (\tilde{g}+d+n(t))+\log h(t)+\xi \Delta \log h(t)+g t+\psi\right)\right]
$$

95. with the speed of convergence given by: $\tilde{\lambda} \equiv(\tilde{g}+d+\bar{n})(1-a) / a$. There are two differences with the transitional dynamics in the augmented Solow model. First, the human capital coefficient is equal to 1 in the Uzawa-Lucas model instead of around 0.5 in the augmented Solow specification. Second, the speed of convergence is much faster in the Uzawa-Lucas approach, as a reasonable order of magnitude is $\tilde{\lambda} \approx(1-1 / 3) /(1 / 3) .(0.05+0.02) \approx 0.14$ instead of 0.02 previously. 


\section{WORKING PAPERS}

The full series of Economics Department Working Papers can be consulted at www.oecd.org/eco/Working_Papers/

601. Estimating a supply block for Poland

(April 2008) Rafal Kierzenkowski, Patric Ollivaud, Franck Sédillot and Philippe Briard

600 Product market regulation and economic performance across Indian states (March 2008) Paul Conway, Richard Herd and Thomas Chalaux

599 Improving product market regulation in India: an international and cross-state comparison (March 2008) Paul Conway and Richard Herd

598. Revenue buoyancy and its fiscal policy implications

(February 2008) Isabelle Joumard and Christophe André

597. Monetary policy, market excesses and financial turmoil

(February 2008) Rudiger Ahrend, Boris Cournède and Robert Price

596. Explaining differences in hours worked among OECD countries: an empirical analysis (February 2008) Sven Blondal and Jean-Marc Burniaux

595. Fiscal policy in India: past reforms and future challenges (February 2008) Richard Herd and Willi Leibfritz

594. The significance of Switzerland's enormous current-account surplus (March 2008) Peter Jarrett and Céline Letremy

593. Interdependencies between monetary policy and foreign-exchange intervention under inflation targeting: the case of Brazil and the Czech Republic

(January 2008) Jean-Yves Gnabo, Luiz de Mello and Diego Moccero

592. Solow or Lucas? Testing growth models using panel data from OECD countries (December 2007) Jens Arnold, Andrea Bassanini and Stefano Scarpetta

591. The private internal rates of return to tertiary education: new estimates for 21 OECD countries (December 2007) Romina Boarini and Hubert Strauss.

590. Making federalism work

(December 2007) Alexandra Bibbee

589. The wage premium on tertiary education: New estimates for 21 OECD countries (December 2007) Hubert Strauss and Christine de la Maisonneuve

588. Enhancing the benefits of financial liberalisation (March 2007) Stefan Ide, Jens Høj and Patrick Lenain

587. Improving incentives in tertiary education (March 2007) Jens Høj 
586. Globalisation and the European Union: which countries are best placed to cope? (December 2007) David Rae and Marte Sollie

585. Primary and secondary education in the United States (November 2007) Peter Tulip and Gregory Wurzburg

584. Financing higher education in the United States (November 2007) Peter Tulip

583. Corporate net lending: a review of recent trends (November 2007) Christophe André, Stéphanie Guichard, Mike Kennedy and David Turner

581. Local government finances: The link between intergovernmental transfers and net worth (September 2007) Luiz de Mello

580. Boosting Austria's innovation performance improving innovation (September 2007) Willi Leibfritz and Jürgen Janger

579. Improving employment prospects in the Slovak Republic: Building on past reforms (September 2007) Andres Fuentes

578. Improving education outcomes in the Slovak Republic (September 2007) David Carey

577. Regulatory reforms in Sweden have boosted productivity (September 2007) Espen Erlandsen and Jens Lundsgaard

576. The policy determinants of investment in tertiary education (September 2007) Joaquim Oliveira Martins, Romina Boarini, Hubert Strauss, Christine de la Maisonneuve and Clarice Saadi

575. Product market competition in the OECD countries: taking stock and moving forward (September 2007) Jens Høj, Miguel Jimenez, Maria Maher, Giuseppe Nicoletti and Michael Wise

574. Too little destruction too little creation: A Schumpeterian diagnosis of barriers to sustained growth in Ukraine

(September 2007) Christian Gianella and William Tompson

573. How do the OECD Growth Projections for the G7 Economies Perform? A post-mortem (September 2007) Lukas Vogel

572. Austria's deepening economic integration with Central and Eastern Europe (August 2007) Rina Bhattacharya

571. Meeting the challenges of decentralization in France (July 2007) Stéphanie Jamet Faire face aux défis de la décentralisation en France (juillet 2007) Stéphanie Jamet

570. Enhancing incentives to improve performance in the education system in France 


\section{ECO/WKP(2008)10}

(July 2007) Paul O’Brien

Renforcer les incitations à une meilleure performance du système éducatif en France

(juillet 2007) Paul O’Brien

569. Combating poverty and social exclusion in France

(July 2007) Stéphanie Jamet

Lutter contre la pauvreté et l'exclusion social en France

(juillet 2007) Stéphanie Jamet

568. The competition law and policy indicator

(July 2007) Jens Hoj

567. Structural policies and economic resilience to shocks

(July 2007) Romain Duval, Jørgen Elmeskov and Lukas Vogel

566. Family policy in Hungary: how to improve the reconciliation between work and family? (July 2007) Philip Hemmings

565. Encouraging sub-national government efficiency in Hungary (July 2007) Alessandro Goglio

564. Integration of immigrants in OECD countries: do policies matter?

(July 2007) Orsetta Causa and Sébastien Jean

563. The unemployment impact of immigration in OECD countries

(July 2007) Sébastien Jean and Miguel Jiménez

562. Migration in OECD countries: labour market impact and integration issues

(July 2007) Sébastien Jean, Orsetta Causa, Miguel Jiminez and Isabelle Wanner

561. The internationalisation of production, international outsourcing and employment in the OECD (June 2007) Margit Molnar, Nigel Pain and Daria Taglioni

560. Why has Swedish inflation been persistently low?

(June 2007) Felix Hüefner

559. The Swedish housing market - better allocation via less regulation

(June 2007) Felix Hüefner and Jens Lundsgaard

558 Linkages between performance and institutions in the primary and secondary education sector (June 2007) Douglas Sutherland and Robert Price

557. Toward a more efficient taxation system in New Zealand (June 2007) Annabelle Mourougane

556. Income inequality, poverty and social spending in Japan (June 2007) Randall Jones

555. Improving the efficiency of health care spending: selected evidence on hospital performance (May 2007) Espen Erlandsen 
554. Cross-country analysis of efficiency in OECD health care sectors: options for research (May 2007) Unto Häkkinen and Isabelle Joumard

553. What promotes fiscal consolidation: OECD country experience

(May 2007) Stéphanie Guichard, Mike Kennedy, Echkard Wurzel and Christophe André

552. Globalisation and the macroeconomic policy environment

(April 2007) Karine Hervé, Isabell Koske, Nigel Pain and Franck Sédillot 